\title{
Spectroscopic investigation and simulation of the crystal field effect as well as paramagnetic behavior of $\mathrm{K}_{2} \mathrm{La}_{1-x} \mathrm{Pr}_{x} \mathrm{Cl}_{5}$ ternary chlorides
}

\author{
Joanna Cybińska ${ }^{\text {a }}$, Janina Legendziewicz ${ }^{\text {a,* }}$, Jorma Hölsä ${ }^{\text {b,* }}$, Mika Lastusaari ${ }^{b}$, \\ Claudia Wickleder ${ }^{\mathrm{c}}$, Gerd Meyer ${ }^{\mathrm{c}}$ \\ ${ }^{\text {a }}$ University of Wrockaw, Faculty of Chemistry, 14 F. Joliot-Curie, PL-50-383 Wrockaw, Poland \\ ${ }^{\mathrm{b}}$ University of Turku, Department of Chemistry, FI-20014 Turku, Finland \\ ${ }^{\mathrm{c}}$ Universität zu Köln, Institut für Anorganische Chemie, Greinstrasse 6, D-50939 Cologne, Germany
}

Received 9 July 2005; accepted 4 October 2005

Available online 13 December 2005

\begin{abstract}
A series of potassium lanthanum praseodymium ternary chlorides, $\mathrm{K}_{2} \mathrm{La}_{1-x} \mathrm{Pr}_{x} \mathrm{Cl}_{5},(0.02 \leqslant x \leqslant 0.15)$ single crystals was grown with Bridgman techniques. The structures of the mixed crystals were found isotypic with that of $\mathrm{K}_{2} \mathrm{PrCl}_{5}$ and $\mathrm{K}_{2} \mathrm{LaCl}_{5}$. The high resolution absorption, luminescence and excitation spectra were recorded at 4,77 and $293 \mathrm{~K}$. Broad band emission of $\mathrm{Pr}^{3+}$ reabsorbed by the ${ }^{3} \mathrm{H}_{4} \rightarrow{ }^{3} \mathrm{P}_{J},{ }_{1}^{1} \mathrm{D}_{2}$ transitions was observed simultaneously with the emission from the ${ }^{3} \mathrm{P}_{0}$ level after excitation in the UV region. The $4 \mathrm{f}^{1} 5 \mathrm{~d}^{1}$ level scheme derived from the absorption, excitation spectra and from VUV synchrotron excitation was partly established. The $4 \mathrm{f}^{2}$ energy level scheme of the $\mathrm{Pr}^{3+}$ ion in $\mathrm{K}_{2} \mathrm{PrCl}_{5}$ consisting of 86 (out of 91) Stark components determined from the absorption and emission spectra was simulated by using a phenomenological crystal field model. The model including eight free ion and nine crystal field parameters (according to the $C_{2 \mathrm{v}}$ symmetry) yielded a rms deviation of $17 \mathrm{~cm}^{-1}$ between the experimental and calculated energy level schemes. Magnetic susceptibility measurements were carried out between 2 and $298 \mathrm{~K}$. Good agreement was obtained between the experimental and calculated paramagnetic susceptibilities as a function of temperature by using the van Vleck formalism and the energies and wave functions derived from the spectral data.
\end{abstract}

(c) 2005 Elsevier B.V. All rights reserved.

Keywords: Dipotassium lanthanum pentachloride; Praseodymium; Absorption; Emission; Excitation; Paramagnetic susceptibility; Crystal field

\section{Introduction}

The development of new phosphors for vacuum ultraviolet (VUV) excitation is an important new challenge in the field of luminescence materials research [1]. In addition to the more conventional luminescent tri- or divalent rare earth $(\mathrm{R})$ ions, i.e. $\mathrm{Eu}^{2+}, \mathrm{Eu}^{3+}$ and $\mathrm{Tb}^{3+}$ [2], praseodymium and cerium compounds seem to be promising for this purpose, too. The trivalent $\mathrm{Ce}^{3+}$ and $\mathrm{Pr}^{3+}$ ions in different crystalline hosts exhibit intense broad band emission due to the parity-allowed electric dipole $4 \mathrm{f}^{N-1} 5 \mathrm{~d}^{1} \rightarrow 4 \mathrm{f}^{N}$ transi-

\footnotetext{
* Corresponding authors. Tel.: +48 71 3757300; fax: +48 713282348.

E-mail addresses: j1@wchuwr.chem.uni.wroc.pl (J. Legendziewicz), jholsa@utu.fi (J. Hölsä).
}

tions ( $N=1$ and 2, respectively) [3]. This emission is of special interest due to their potential applications in fast scintillators (decay times down to $10 \mathrm{~ns}$ ) and ultraviolet tunable laser devices [4]. In addition to the sharp line emission due to the intraconfigurational $4 \mathrm{f}-4 \mathrm{f}$ transitions, the emission of trivalent praseodymium occurs as wide bands in the near UV region, if the lowest $5 \mathrm{~d}$ state is located below the $4 \mathrm{f}^{N}\left({ }^{1} \mathrm{~S}_{0}\right)$ state due to the strong coupling between the $5 \mathrm{~d}$ electron and the lattice phonons. If the location of the $5 \mathrm{~d}$ states is at higher energy than the ${ }^{1} \mathrm{~S}_{0}$ state photon cascade emission can be observed $[5,6]$. Thus it is interesting to investigate the luminescence of $\mathrm{Pr}^{3+}$ ions in different host lattices.

The luminescence properties of the $\mathrm{K}_{2} \mathrm{RCl}_{5}$ compounds with both actinide and lanthanide doping have been 
studied especially for keeping the scintillator applications in mind. The ions studied include $\mathrm{Ce}^{3+}[7-9], \mathrm{U}^{3+}[10,11]$, $\mathrm{Er}^{3+}$ [12] and $\mathrm{K}_{2} \mathrm{UBr}_{5}$ [13], and $\mathrm{K}_{2} \mathrm{EuCl}_{5}$ [14]. The aims of the previous investigations also include the study of the magnetic phase transitions as well as an analysis of the crystal field (c.f.) effect in the chloride host matrix.

The aim of the present investigation was to characterize in detail the effect of the crystal field on the $4 \mathrm{f}^{2}$ energy level scheme of the $\mathrm{Pr}^{3+}$ ion in both the non-doped $\mathrm{K}_{2} \mathrm{PrCl}_{5}$ and the mixed $\mathrm{K}_{2}(\mathrm{La}, \mathrm{Pr}) \mathrm{Cl}_{5}$ single crystals. This was achieved with the aid of the phenomenological simulation based on experimental spectroscopic data and partly also by using the extended electrostatic point charge model. The results on the effect of the crystal field are compared to those obtained for the corresponding $\mathrm{Pr}^{3+}$ doped fluoride, $\mathrm{K}_{2}(\mathrm{Y}, \mathrm{Pr}) \mathrm{F}_{5}[15,16]$. The evolution of the paramagnetic susceptibility as a function of temperature was interpreted by using the data based on the spectroscopic investigations. Finally, the UV excitation and emission due to the $4 \mathrm{f}^{2} \leftrightarrow 4 \mathrm{f}^{1} 5 \mathrm{~d}^{1}$ transitions was studied.

\section{Experimental}

\subsection{Sample preparation}

The mixed $\mathrm{K}_{2}(\mathrm{La}, \mathrm{Pr}) \mathrm{Cl}_{5}$ single crystals were grown in a quartz ampoule from a melt by using the Bridgman technique according to the procedure described earlier $[17,18]$. The melt was obtained by heating the appropriate amounts of the starting materials $\left(\mathrm{KCl}, \mathrm{LaCl}_{3}\right.$ and $\left.\mathrm{PrCl}_{3}\right)$ which were purified prior to the reaction by sublimation in a tantalum ampoule. Cooling of the melt from the starting temperature $\left(640^{\circ} \mathrm{C}\right)$ was carried out in two steps: first to $470{ }^{\circ} \mathrm{C}$ with a rate of 1 degree/h and then to the room temperature with a rate of 5 degrees $/ \mathrm{h}$. The $\operatorname{Pr}^{3+}$ dopant concentration was varied between 2 and $15 \mathrm{~mol} \%$ of the total rare earth content. In the case of doped samples large crystals up to $1 \mathrm{~cm}$ in diameter could be grown. The effort to polish the oriented crystals failed, they were cracked, because of their morphology. Thus the polarized spectra of the oriented crystals could not be measured.

The samples were found rather moisture-sensitive and were handled under anhydrous conditions. The cutting, sanding and polishing of the crystals were carried out with paraffin oil in a dry box. In this way samples with parallel faces and with thicknesses of several $\mathrm{mm}$ were obtained. Prior to the spectroscopic and magnetic measurements, the X-ray diffraction was used to check the purity and structure of the samples.

\subsection{Spectroscopic measurements}

\subsubsection{Absorption spectra}

For the absorption measurements, the $\mathrm{K}_{2}(\mathrm{La}, \mathrm{Pr}) \mathrm{Cl}_{5}$ (or $\mathrm{K}_{2} \mathrm{PrCl}_{5}$ ) single crystals treated in a way described above were confined between two quartz plates. The orientation of the crystals was random. Because of the low site symme- try $\left(C_{\mathrm{s}}\right)$ of the $\mathrm{R}^{3+}$ site the information obtained by the measurements with polarized radiation was not interpretable. This was also suggested earlier [11]. The absorption spectra in the UV region at $293 \mathrm{~K}$ were recorded for three $(2,5$, and $15 \mathrm{~mol} \%)$ concentrations for respective thicknesses of the crystals. The absorption spectra were recorded at 4 and $293 \mathrm{~K}$ with a Cary-Varian 500 Scan spectrometer equipped with an Oxford helium flow cryostat.

\subsubsection{Luminescence spectra}

The low resolution luminescence spectra excited by a $450 \mathrm{~W}$ Oriel xenon lamp in the UV region with wide band excitation at 280, 248 and $308 \mathrm{~nm}$ as well as the excitation spectra at 77 and $293 \mathrm{~K}$ were recorded between 320 and $750 \mathrm{~nm}$ with an Aminco SPF-500 spectrofluorometer with a resolution of $0.1 \mathrm{~nm}$.

The high resolution luminescence spectra with a resolution of $0.01 \mathrm{~nm}$ were detected between 470 and $1500 \mathrm{~nm}$ by using an Action Research Corporation Spectra Pro 750 monochromator equipped with a Hamamatsu R 928 photomultiplier as the detector. A $450 \mathrm{~W}$ xenon lamp, $\mathrm{Nd}$ :YAG laser, $\mathrm{XeCl}$ excimer laser and an $\mathrm{Ar}^{+}$ion laser $(457.9 \mathrm{~nm})$ were used as alternative excitation sources. A specially prepared quartz tube was used to assure the best conditions for detection of luminescence at 4, 77 and $293 \mathrm{~K}$. The VUV and UV excitation spectra of the ${ }^{3} \mathrm{P}_{0} \rightarrow{ }^{3} \mathrm{H}_{4}$ transition (at $494 \mathrm{~nm}$ ) between 10 and $240 \mathrm{~nm}$ as well as the respective emission spectra were obtained by using synchrotron radiation (DESY synchrotron, Hamburg Synchrotron Radiation Laboratory HASYLAB, Germany).

\subsection{Structural considerations}

The non-doped $\mathrm{K}_{2} \mathrm{PrCl}_{5}$ crystallizes in the orthorhombic centrosymmetric space group Pnma- $\mathrm{D}_{2 \mathrm{~h}}^{16}(\# 62, Z=4)$ with the lattice constants $a=12.631(8), b=8.756(3)$, and $c=7.973(4) \AA$ [17]. The crystal structures of the mixed $\mathrm{K}_{2}(\mathrm{La}, \mathrm{Pr}) \mathrm{Cl}_{5}$ single crystals were found to be isotypic with that of the non-doped compound. All $\mathrm{Pr}^{3+}$ ions are crystallographically identical. The overall crystal structure of $\mathrm{K}_{2} \mathrm{PrCl}_{5}$ consists of $\mathrm{PrCl}_{7}$ polyhedra connected by two common edges to form infinite chains running along the crystallographic $b$-axis (Fig. 1). The chains are arranged like a hexagonal packing of rods and are held together by potassium ions. The intrachain $\operatorname{Pr}^{3+}-\operatorname{Pr}^{3+}$ distances are all equal to $4.550 \AA$. Other $\operatorname{Pr}^{3+}-\operatorname{Pr}^{3+}$ distances are much longer, starting from $6.89 \AA$.

Seven $\mathrm{Cl}^{-}$ions coordinate the $\mathrm{Pr}^{3+}$ ion in the form of a distorted monocapped trigonal prism (Fig. 2). The point symmetry of the $\operatorname{Pr}^{3+}$ site is low, $C_{\mathrm{s}}$ instead of the ideal $C_{2 \mathrm{v}}$ point symmetry for the monocapped trigonal prism coordination. The coordination number 7 is rather low for such a large $\mathrm{R}^{3+}$ ion as $\operatorname{Pr}^{3+}$ and this factor together with the electrostatically rather soft anion, $\mathrm{Cl}^{-}$, may well affect the strength of the crystal field around the $\mathrm{Pr}^{3+}$ ion to the weaker side. A closer scrutiny of the structural data 


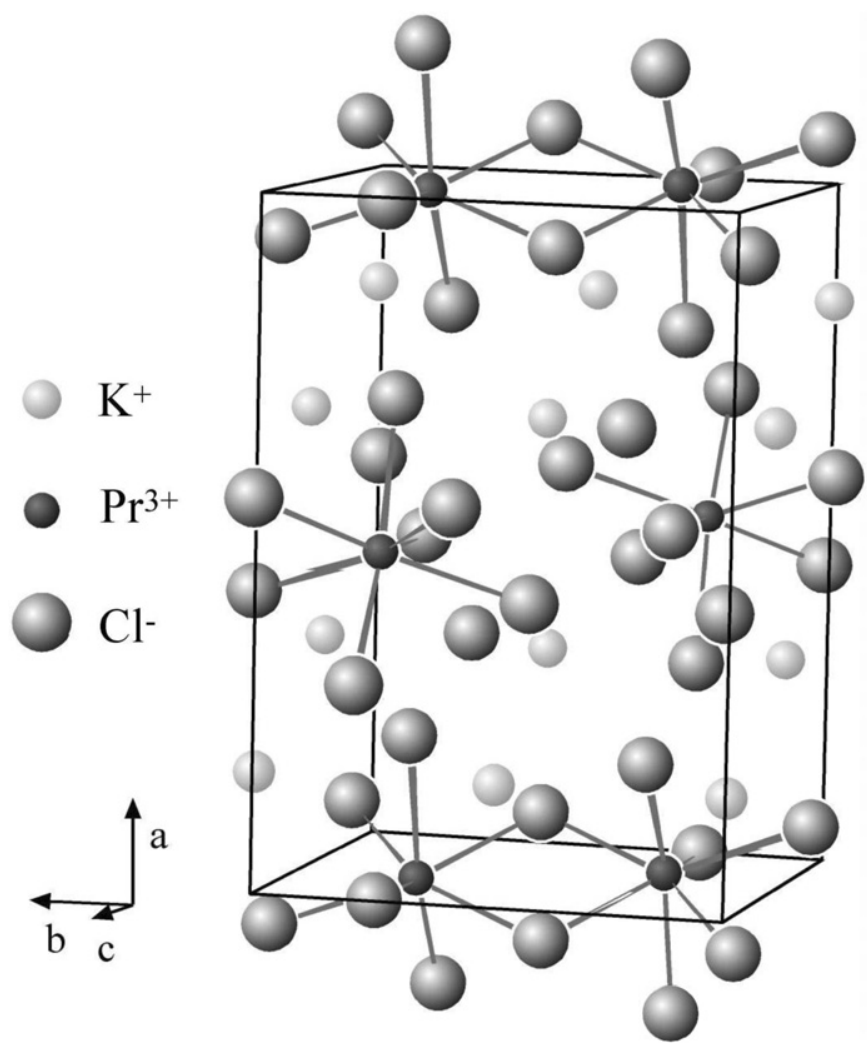

Fig. 1. The overall crystal structure of $\mathrm{K}_{2} \mathrm{PrCl}_{5}$ consisting of $\mathrm{PrCl}_{7}$ units connected by two common edges to form infinite chains running along the crystallographic $b$-axis.

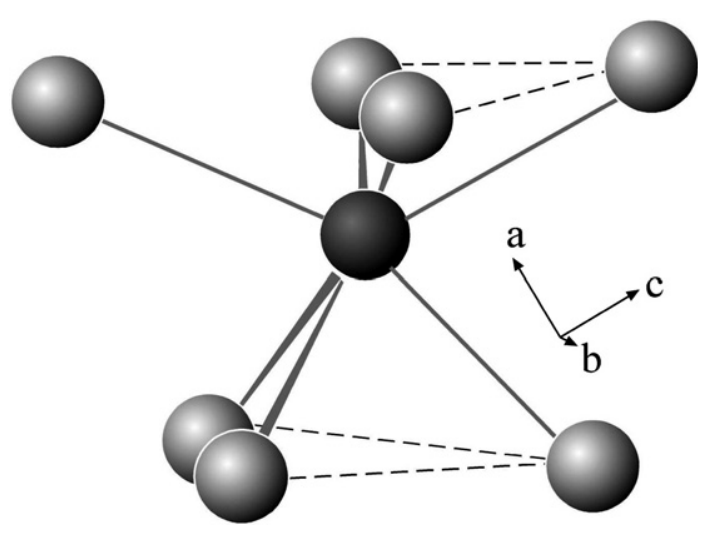

Fig. 2. The $\mathrm{PrCl}_{7}$ units of $\mathrm{K}_{2} \mathrm{PrCl}_{5}$ forming a distorted monocapped trigonal prism as a coordination polyhedron around the $\mathrm{Pr}^{3+}$ ion.

implies that the $\mathrm{Pr}-\mathrm{Cl}$ bond distances $(2.858(2 \times), 2.824(2 \times)$, $2.792,2.788$ and $2.752 \AA$ ) [18] differ significantly from any higher, e.g. $C_{2 \mathrm{v}}$, symmetry. Also the $\mathrm{Cl}-\mathrm{Pr}-\mathrm{Cl}$ bond angles do not resemble to those for any reasonable higher than $C_{\mathrm{s}}$ point symmetry. However, the deviation from $C_{2 \mathrm{v}}$ is not dramatically large. New, more precise X-ray data points at a more symmetric coordination polyhedron [18].

The crystal structure of the related fluoride phase with the same stoichiometry, $\mathrm{K}_{2} \mathrm{RF}_{5}$, has been subject to much debate since up to date several different structures-partly depending on the rare earth cation-have been proposed [19]. However, according to the seemingly most reliable investigation [20], it is clear that the smaller rare earth fluorides (beyond $\mathrm{R}=\mathrm{Pr}$ ) crystallize in the same type of structure as the corresponding chlorides. The point symmetry of the $\operatorname{Pr}^{3+}$ site in $\mathrm{K}_{2}(\mathrm{Y}, \mathrm{Pr}) \mathrm{F}_{5}$ is thus $C_{\mathrm{s}}$. It would thus be of interest to compare the present results for the $\mathrm{K}_{2} \mathrm{PrCl}_{5}$ system with those obtained for the $\mathrm{K}_{2}(\mathrm{Y}, \mathrm{Pr}) \mathrm{F}_{5}$ [15] system even if the Pr-F distances are somewhat shorter than the $\mathrm{Pr}-\mathrm{Cl}$ ones and the c.f. effect should be clearly different in these two compounds.

\subsection{Energy level scheme calculations}

The complex energy level schemes of the $\mathrm{R}^{3+}$ ions in solid state result from several interactions-both within the $4 \mathrm{f}^{N}$ electron configuration and between the $\mathrm{R}^{3+}$ ion and its environment [21]. Each interaction can be described with the aid of effective operators and their effect can be parametrized by using phenomenological models. The Coulombic interaction between the $4 \mathrm{f}$ electrons is described with the Slater integrals $F^{k}(k=0,2,4$, and 6) or Racah parameters $E_{k}(k=0,1,2$, and 3$)$. The spin-orbit coupling taken into account by the coupling constant $\zeta_{4 \mathrm{f}}$ splits the ${ }^{2 S+1} \mathrm{~L}$ terms into the ${ }^{2 S+1} \mathrm{~L}_{J}$ levels. $\alpha, \beta$ and $\gamma$ describe the two-body electrostatic Trees parameters, whereas the Judd parameters $T^{k}$ are the corresponding three-body interactions. The effective Hamiltonian $H_{\mathrm{FI}}$ comprising these interactions can be written as follows:

$$
\begin{aligned}
H_{\mathrm{FI}}= & \sum_{k=0}^{3} E_{k}(n f, n f) e^{k}+\zeta_{4 \mathrm{f}} A_{\mathrm{SO}}+\alpha L(L+1) \\
& +\beta G\left(G_{2}\right)+\gamma G\left(R_{7}\right)+\sum_{k=2,3,4,6,7,8} T^{k} t_{k}
\end{aligned}
$$

where the angular parts $e^{k}, A_{\mathrm{SO}}, L, G\left(G_{2}\right), G\left(R_{7}\right)$, and $t_{k}$ have their usual meanings [21,22]. Higher-order magnetic spin-spin and spin-other orbit interactions as well as the electrostatically correlated spin-orbit interactions can be parameterized by the Marvin integrals $M^{k}(k=0,2$, and 4) and $P^{k}(k=2,4$, and 6) parameters, respectively.

When the $\mathrm{R}^{3+}$ ion is introduced into a solid it experiences an inhomogeneous electrostatic field created by the surrounding charge distribution. The c.f. Hamiltonian $H_{\mathrm{CF}}$ can be obtained as follows [21]:

$H_{\mathrm{CF}}=\sum_{k} \sum_{q=-k}^{q=k}\left\{B_{q}^{k}\left[C_{q}^{k}+(-1)^{q} C_{-q}^{k}\right]+\mathrm{i} S_{q}^{k}\left[C_{q}^{k}-(-1)^{-q} C_{-q}^{k}\right]\right\}$

where the parameters $B_{q}^{k}$ and $S_{q}^{k}$ are the coefficients of the c.f. expansion, i.e. the real and imaginary functions of the radial distances, respectively. $C_{q}^{k}$ s are tensor operators of rank $k$ closely related to the spherical harmonics.

The phenomenological simulation of the c.f. energy level scheme of the $\mathrm{R}^{3+}$ ions involves the determination of a large number of parameters (even more than 30) from 
the experimentally determined energy level scheme. For the $\mathrm{Pr}^{3+}$ ion dealt in this study, the situation is quite different. For the $4 \mathrm{f}^{2}$ electron configuration, only eight free ion parameters are needed to describe the experimental data. The three-body interaction parameters (i.e. the Judd parameters $T^{k}$ ) are not allowed for the $\operatorname{Pr}^{3+}$ ion and the use of the Marvin integrals was considered unnecessary, as well, since their effect was expected to be restricted mainly to the well-isolated highest level, ${ }^{1} \mathrm{~S}_{0}$.

The $4 \mathrm{f}^{2}$ electron configuration of the $\operatorname{Pr}^{3+}$ ion is not very complex with 91 c.f. levels, either. The simulations of the c.f. effect for the $\mathrm{Pr}^{3+}$ ion in different host matrices are thus usually carried out without any greater technical problems $[23,24]$. This was not, however, the case with the present study. The main problem with the present calculations was due to the low point symmetry $\left(C_{\mathrm{s}}\right)$ of the $\operatorname{Pr}^{3+}$ ion site in the $\mathrm{K}_{2}(\mathrm{La}, \mathrm{Pr}) \mathrm{Cl}_{5}$ host lattice. For the $C_{\mathrm{s}}$ point symmetry the c.f. expansion contains a high number of terms, in total 15 c.f. parameters including six imaginary terms in addition to nine real ones [25]. In order to avoid the low symmetry problem, much debate and different approaches-both experimental and theoretical-have been taken in the previous studies $[10,11]$. However, this problem has not been solved up to date. As the most evident possibility, the use of the descending symmetry approach appeared into the minds of the authors, but, from the structural point of view, the use of this approach seems rather futile as shown above. On the other hand, a detailed and systematic study of the partial energy level scheme of the $\mathrm{Eu}^{3+}$ ion in an isomorphous $\mathrm{K}_{2} \mathrm{EuCl}_{5}$ host [14] shows that - at least somesplittings of the ${ }^{7} \mathrm{~F}_{J}$ levels induced by the c.f. effect are small, indeed. Similar small c.f. splittings of the $\mathrm{Pr}^{3+}$ levels were found also in this study and reported earlier [26]. Accordingly, instead of carrying out pointless low symmetry c.f. calculations with too many parameters and without any physical and chemical meaning the low symmetry problem was tried to be avoided in this study by using the higher $C_{2 \mathrm{v}}$ point symmetry for the $\operatorname{Pr}^{3+}$ ion site. It should be emphasized, that there was not in the beginning of the study any clear a priori certainty that the pitfalls involved in the use of low symmetry simulation could be avoided.

As far as the final stage of the simulation process is concerned, the best fit set of the c.f. parameters was obtained through minimizing the conventional rms function between the observed and calculated energy level values with the standard least squares refinement by using the program REEL [27]. The $C_{2 \mathrm{v}}$ symmetry was used in the calculations which symmetry requires a separate diagonalization of two square matrices which correspond to the levels with the irreducible representations $\mathrm{A}$ and $\mathrm{B}$. The dimensions of these matrices were $49 \times 49$ and $42 \times 42$, respectively. However, an effort was made to simulate the c.f. energy level scheme of $\mathrm{Pr}^{3+}$ in $\mathrm{K}_{2} \mathrm{LaCl}_{5}$ matrix including also the Marvin integrals and calculations were performed for the $C_{\mathrm{s}}$ symmetry to analyze this approach on the c.f. parameters and $\operatorname{Pr}^{3+}$ energy levels [26].

\subsection{Magnetic measurements}

The magnetic susceptibility measurements were carried out with a Quantum Design MPMS-5 superconducting quantum interference device (SQUID) magnetometer at temperatures between 2 and $298 \mathrm{~K}$ in both the low and high field regimes $(0-5 \mathrm{~T})$. The data presented in this work were obtained with the field of $0.5 \mathrm{~T}$. The experimental susceptibility values were corrected for the diamagnetic contribution by using the standard values for the $\mathrm{La}^{3+}, \mathrm{Pr}^{3+}, \mathrm{K}^{+}$, and $\mathrm{Cl}^{-}$ions [28].

For the rare earth compounds the difference between the experimental paramagnetic susceptibility and that predicted by the Curie-Weiss law, $\chi=C /(T-\theta)$, at low temperatures is generally due to the c.f. effect. The inadequacy of the Curie-Weiss law can be accounted for by using the formalism presented by van Vleck $[29,30]$ :

$$
\begin{aligned}
& \chi=N_{\mathrm{A}} \beta^{2} \sum_{i}\left(\frac{\left\langle\Phi_{i}|\mu| \Phi_{i}\right\rangle^{2}}{k T}-2 \sum_{i \neq j} \frac{\left\langle\Phi_{i}|\mu| \Phi_{j}\right\rangle\left\langle\Phi_{j}|\mu| \Phi_{i}\right\rangle}{E_{i}-E_{j}}\right) B_{i} \\
& B_{i}=\frac{\exp \left(-E_{i} / k T\right)}{\sum_{i} d_{i} \exp \left(-E_{i} / k T\right)}
\end{aligned}
$$

In this expression $B_{i}$ is the thermal population coefficient for the energy levels according to the Boltzmann partition law and $N_{\mathrm{A}}, \beta, \Phi$, and $E$ are the Avogadro constant, the Bohr magneton, and the non-perturbed wave functions as well as the level energies in the absence of a magnetic field, respectively. The wave functions and energies were determined from the treatment of the spectroscopic data to be presented later in Section 3.4. The degeneracy of the energy levels is accounted for by the term $d_{i}$. The actual calculations were carried out with the program package REEL [27].

\subsection{Extended electrostatic point charge model calculations}

It is well known that the magnitude of the free ion interactions, i.e. the Coulombic repulsion between the $4 \mathrm{f}$ electrons, spin-orbit coupling and configuration interactions, do not change much from one lattice to another $[23,24]$. Accordingly, the choice of the exact values for the free ion interactions was not the critical point of the calculations. For the $C_{2 \mathrm{v}}$ point symmetry the c.f. expansion (Eq. (2)) contains only a relatively low number of terms, in total nine real c.f. parameters including no imaginary terms. Despite the reduced number of terms the starting point for the actual simulation was not easy since the earlier works $[10,11]$ gave no reasonable starting set of c.f. parameters for the phenomenological treatment. At this stage, it was decided that some additional information was needed from the theory.

Apart from the phenomenological simulation of the energy level schemes of the $\mathrm{R}^{3+}$ ions $[31,32]$, another possibility to obtain the individual c.f. parameters is to calculate them directly from structural data using the (Extended) 
Electrostatic Point Charge PCEM [33] or the simple overlap SOM models $[34,35]$. In the PCEM case, the $B_{q}^{k}$ parameters can be expressed as products between the $\mathrm{R}^{3+}$ ion radial integrals $\left\langle r^{k}\right\rangle$ and the lattice sums $A_{q}^{k}$ which depend only on the doping ion and the host lattice, respectively (Eq. (4)) [33]:

$B_{q}^{k}=\tau^{-k}\left(1-\sigma^{k}\right) A_{q}^{k}\left\langle r^{k}\right\rangle$

The radial integrals $\left\langle r^{k}\right\rangle[36]$ are subject to two corrections: the factors $\tau\left(0.74908\right.$ for $\left.\operatorname{Pr}^{3+}[31]\right)$ and $\sigma^{k}(k=2,4$, and 6) describe the expansion of the $4 \mathrm{f}$ wave functions in the solid state and the shielding effect of the $6 \mathrm{~s}, 5 \mathrm{~d}$ and $5 \mathrm{p}$ electrons, respectively. For the $\operatorname{Pr}^{3+}$ ion the $\sigma^{k}$ values used in the calculations were as follows: $0.666,0.09$, and -0.04 for $k=2$, 4 , and 6, respectively [33]. The lattice sums $A_{q}^{k}$ can be corrected for the effective charges of the ions and for the local distortions around the $\mathrm{R}^{3+}$ ion. Even if the former can be obtained from e.g. the spectroscopic (XPS) investigations [37] the latter are usually not known exactly and can be approximated only with low reliability [38]. Consequently, the correction for local distortions is not usually applied in calculations. For the different ions in $\mathrm{K}_{2} \mathrm{PrCl}_{5}$, the effective charges used in the calculations were as follows: $+1.5,0.5$, and -0.5 for the $\mathrm{Pr}, \mathrm{K}$, and $\mathrm{Cl}$ ions, respectively. The lattice sum $\mathrm{A}_{q}^{k}$ parameters were calculated with the program SOMAILLE [39].

\subsection{Crystal field strength}

In order to compare in a reliable and uniform manner the effect of the surrounding lattice on different $\mathrm{R}^{3+}$ ions doped in various host with different site symmetries, the concept of the c.f. strength parameter $N_{V}$ [40] (or S [41]) is frequently used. The parameters can be shown to be closely related, but the former formalism was followed in this work (Eq. (5)) [40]:

$N_{V}=\left[\sum_{k, q}\left(\frac{4 \pi}{2 k+1}\right)\left|B_{q}^{k}\right|^{2}\right]^{1 / 2}$

The c.f. strength parameter $N_{V}$ is essentially a root square sum of the individual c.f. parameters weighed with their rank $k$ in order to compensate for the different number of parameters. It is evident that some detailed information is lost in this process but the problem of comparison of the c.f. effect between different site symmetries can not be avoided in any other way.

\section{Results and discussion}

\subsection{Analysis of the $4 f^{1} 5 d^{l}$ energy level scheme}

The absorption spectra of the doped $\mathrm{K}_{2}(\mathrm{La}, \mathrm{Pr}) \mathrm{Cl}_{5}$ crystals $\left(x_{\operatorname{Pr}}=0.02,0.05,0.15\right.$ and 1.00) show some interesting features (Figs. 3 and 4). The absorption in the UV region is dominated by the parity allowed interconfigurational $4 \mathrm{f}^{2} \rightarrow 4 \mathrm{f}^{1} 5 \mathrm{~d}^{1}$ transitions, very intense even for the crystals at such a low doping level (Fig. 4). The parity forbidden $4 \mathrm{f}^{2} \rightarrow 4 \mathrm{f}^{2}$ transitions are observed in the visible and IR regions with much lower intensities, however. The $4 \mathrm{f}^{2} \rightarrow 4 \mathrm{f}^{1} 5 \mathrm{~d}^{1}$ bands are much wider than the $4 \mathrm{f}^{2} \rightarrow 4 \mathrm{f}^{2}$ transitions because of the strong coupling between the $5 \mathrm{~d}$ electron and the lattice phonons. The energies of the $4 \mathrm{f}^{N-1} 5 \mathrm{~d}^{1}$ levels are much more influenced by the c.f. interaction than those of the $4 \mathrm{f}^{N}$ levels. This is due to the strong interaction of the $5 \mathrm{~d}$ electrons with the neighboring anions in solid state. The $4 \mathrm{f}^{2} \rightarrow 4 \mathrm{f}^{1} 5 \mathrm{~d}^{1}$ spectra in $\mathrm{K}_{2}(\mathrm{La}, \mathrm{Pr}) \mathrm{Cl}_{5}$ are

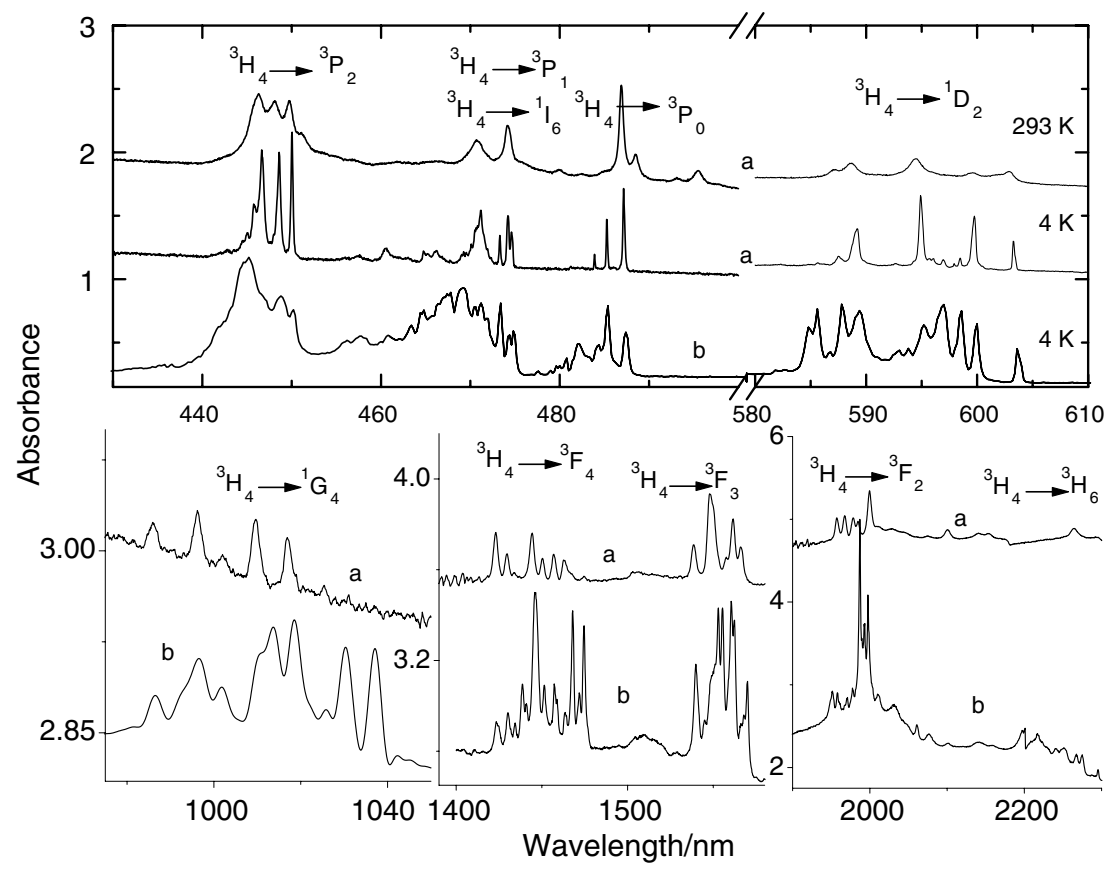

Fig. 3. The absorption spectra of $\mathrm{K}_{2}\left(\mathrm{La}_{0.95} \mathrm{Pr}_{0.05}\right) \mathrm{Cl}_{5}$ (a) and $\mathrm{K}_{2} \mathrm{PrCl}_{5}$ (b) at 293 and $4 \mathrm{~K}$. 


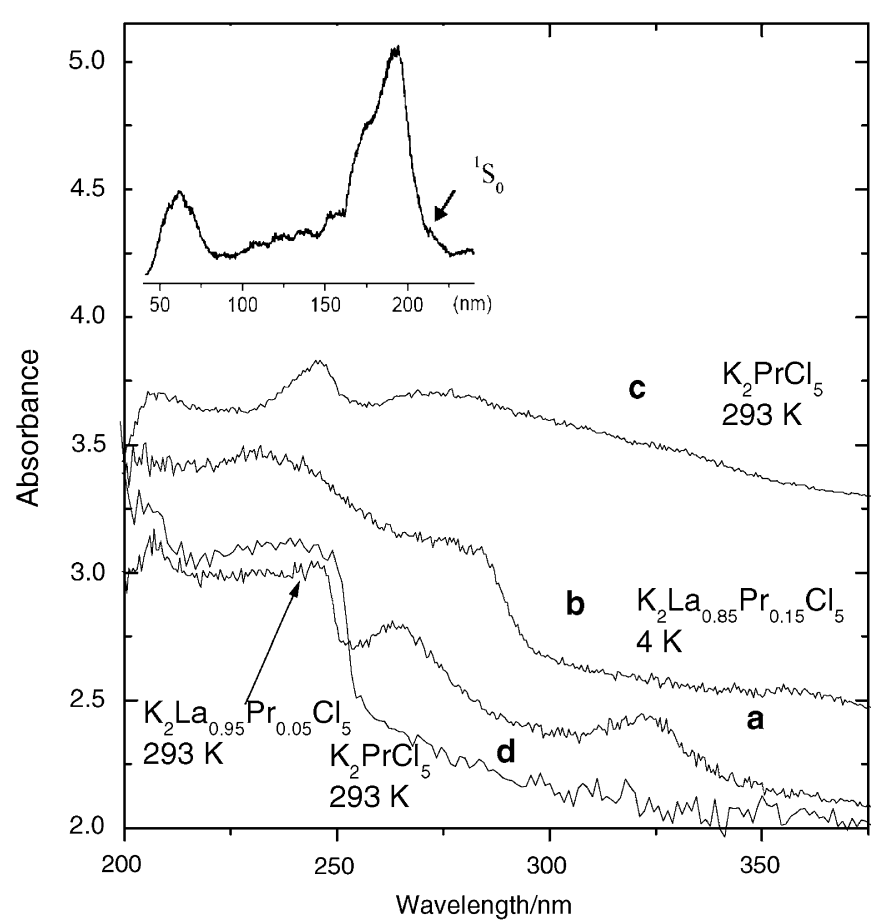

Fig. 4. Absorption (a, b, d) and reflection (c) spectra of $\mathrm{K}_{2} \mathrm{La}_{0.95} \mathrm{Pr}_{0.05} \mathrm{Cl}_{5}$, $\mathrm{K}_{2} \mathrm{La}_{0.85} \mathrm{Pr}_{1.05} \mathrm{Cl}_{5}$ and $\mathrm{K}_{2} \mathrm{PrCl}_{5}$ at 293 and $4 \mathrm{~K}$. Inset shows the $\mathrm{UV}$ and VUV synchrotron excitation spectrum of the ${ }^{3} \mathrm{P}_{0} \rightarrow{ }^{3} \mathrm{H}_{4}$ transition $(494 \mathrm{~nm})$ of the $\mathrm{K}_{2}\left(\mathrm{La}_{0.98} \mathrm{Pr}_{0.02}\right) \mathrm{Cl}_{5}$ single crystal at $8 \mathrm{~K}$.

composed of four bands located at 220, 245, 263 and $323 \mathrm{~nm}$ instead of the five components expected for the low point symmetry of the $\operatorname{Pr}^{3+}$ site $\left(C_{\mathrm{s}}\right)$. The energies and intensities of the respective bands vary only slightly along the concentration of the dopant but are significantly different from the spectrum of the stoichiometric $\mathrm{K}_{2} \mathrm{PrCl}_{5}$ ternary chloride, where only one broad band at $250 \mathrm{~nm}$ was observed with a noticeable increase in intensity starting already at $300 \mathrm{~nm}$. At energies higher than $45,500 \mathrm{~cm}^{-1}(220 \mathrm{~nm})$ a drastic increase in absorption was detected. According to the data for $\mathrm{K}_{2}(\mathrm{La}, \mathrm{Ce}) \mathrm{Cl}_{5}[7,8]$, the spread in the $4 \mathrm{f}^{1} \rightarrow 4 \mathrm{f}^{0} 5 \mathrm{~d}^{1}$ transition is equal to $15,128 \mathrm{~cm}^{-1}$ and that for $\mathrm{K}_{2}(\mathrm{La}, \mathrm{Pr}) \mathrm{Cl}_{5}$ should be comparable. Moreover, based on the earlier considerations [9], the first $4 \mathrm{f}^{2} \rightarrow 4 \mathrm{f}^{1} 5 \mathrm{~d}^{1}$ band for $\operatorname{Pr}^{3+}$ in the same matrix could be expected at an energy close to $42,000 \mathrm{~cm}^{-1}(240 \mathrm{~nm})$. This corresponds well to the observations for the stoichiometric $\mathrm{K}_{2} \mathrm{PrCl}_{5}$ sample (Fig. 4). On the other hand, Andres et al. [11] pointed on the shift of d levels from $46,000 \mathrm{~cm}^{-1}$ to $15,000 \mathrm{~cm}^{-1}$ for $\mathrm{K}_{2}(\mathrm{La}, \mathrm{Nd}) \mathrm{Cl}_{5}$ and the $\mathrm{U}^{3+}$ doped compound, respectively. If so, keeping in mind the rules formulated by Dorenbos, the first $5 \mathrm{~d}$ level should expected at $277 \mathrm{~nm}$ for $\operatorname{Pr}^{3+}$.

On the other hand, assuming the band located at $323 \mathrm{~nm}$ as the first level of the $4 \mathrm{f}^{2} \rightarrow 4 \mathrm{f}^{1} 5 \mathrm{~d}^{1}$ transition and the splitting of the $4 \mathrm{f}^{1} 5 \mathrm{~d}^{1}$ configuration to be $15,000 \mathrm{~cm}^{-1}$, the higher levels should be observed at $215 \mathrm{~nm}\left(46,500 \mathrm{~cm}^{-1}\right)$. Other possibilities can be also considered: the first two bands are due to impurities, whereas the next band is a $4 \mathrm{f}^{2} \rightarrow 4 \mathrm{f}^{1} 5 \mathrm{~d}^{1}$ transition of $\operatorname{Pr}^{3+}$, i.e. the first level is at $40,000 \mathrm{~cm}^{-1}(250 \mathrm{~nm})$. Thus the last level could be at
$55,100 \mathrm{~cm}^{-1}(181 \mathrm{~nm})$ and one of former levels should be seen at $51,300 \mathrm{~cm}^{-1}(194 \mathrm{~nm})$.

The excitation spectra were recorded by monitoring the luminescence of the ${ }^{3} \mathrm{P}_{0} \rightarrow{ }^{3} \mathrm{H}_{4}$ transition at $494 \mathrm{~nm}$ (Fig. 4 inset) for the $\mathrm{K}_{2}\left(\mathrm{La}_{0.98} \mathrm{Pr}_{0.02}\right) \mathrm{Cl}_{5}$ crystal at $8 \mathrm{~K}$ with the synchrotron radiation. In the range between 40 and $220 \mathrm{~nm}$ one can find a split band spreading from $150 \mathrm{~nm}$ to $210 \mathrm{~nm}$ where the two components are well separated (ca. $3800 \mathrm{~cm}^{-1}$ ) at ca. 175 and at ca. $190 \mathrm{~nm}$. These band positions correspond well to those calculated on the data reported for $\mathrm{K}_{2}(\mathrm{LaCe}) \mathrm{Cl}_{5}$ [7-9]. These bands can overlap with the host absorption of $\mathrm{K}_{2} \mathrm{LaCl}_{5}$ as reported for other lanthanide chlorides $[8,42]$. Nevertheless, they may also be related to the hygroscopic nature of the materials creating impurities mainly on the surface. It should be noted that the ${ }^{1} \mathrm{~S}_{0}$ level was observed as a very weak signal around $214 \mathrm{~nm}$ (Fig. 4 inset) and thus the energy of this level could be defined.

\subsection{Analysis of absorption spectra}

The $4 \mathrm{f}^{2}$ ground configuration of the $\mathrm{Pr}^{3+}$ ion gives rise to $13{ }^{2 S+1} \mathrm{~L}_{J}$ levels (Fig. 5) all of which except the ${ }^{1} \mathrm{~S}_{0}$ level

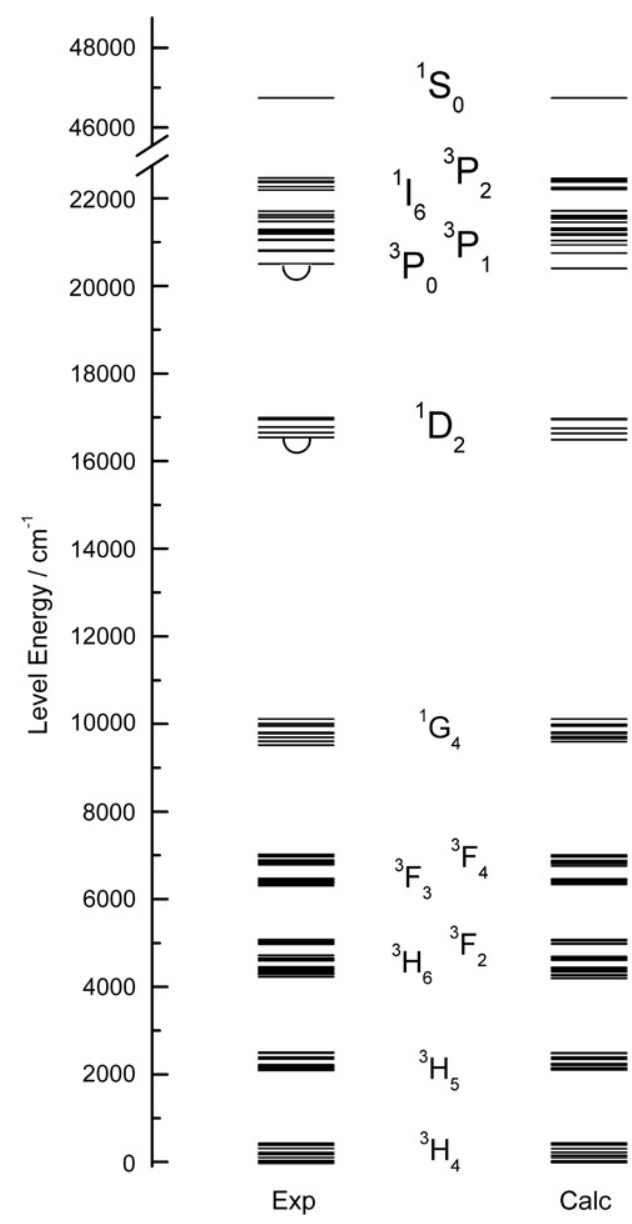

Fig. 5. The calculated and experimental energy level schemes for the $\operatorname{Pr}^{3+}$ ion $\left(4 \mathrm{f}^{2}\right.$ electron configuration) in $\mathrm{K}_{2}(\mathrm{La}, \mathrm{Pr}) \mathrm{Cl}_{5}$. 
situate below $25,000 \mathrm{~cm}^{-1}$. This means that practically all levels of the $4 \mathrm{f}^{2}$ electron configuration are accessible by one photon absorption or luminescence in the visible or IR range. The electric dipole transitions within the $4 \mathrm{f}^{2}$ configuration are strictly forbidden for the free ion case but the electrostatic c.f. effect lifts this restriction in solid state by mixing the $4 \mathrm{f}^{2}$ wave functions with those of configurations with opposite parity, e.g. those of $4 \mathrm{f}^{1} 5 \mathrm{~d}^{1}$ [21]. Transitions of magnetic dipole origin can be observed, too, even if the electric dipole transitions were found to be dominant in the case of the $\mathrm{Pr}^{3+}$ ion. The c.f. effect, in addition to mixing the wave functions, lifts the $(2 J+1)$ degeneracy of the free ion ${ }^{2 S+1} \mathrm{~L}_{J}$ levels to an extent determined by the crystal structure of the host lattice [23]. For the low $C_{\mathrm{s}}$ point symmetry appropriate to the $\mathrm{K}_{2}(\mathrm{La}, \mathrm{Pr}) \mathrm{Cl}_{5}$ host matrices, this degeneracy was found experimentally to be completely lifted in accordance with the theoretical predictions. Note also that some lines were very weak.

Even at low temperatures where the hot band absorption should be negligible, the number of lines in the absorption spectra was sometimes found greater than the maximum allowed by the quantum number $J$. For statistical reasons, even at a low doping level (e.g. $\left.x_{\operatorname{Pr}}=0.02\right)$, the distribution of the $\operatorname{Pr}^{3+}$ dopant ions is not completely uniform - though it may be random-but allows the existence of pairs of the $\operatorname{Pr}^{3+}$ ions linked by $\mathrm{Cl}^{-}$ions. Especially along the crystallographic $b$-axis (Fig. 1) the interaction within the pairs should not be negligible. Accordingly, the additional lines may arise from these pairs since the energies of the single ion energy levels are slightly modified due to the pair formation $[43,44]$. On the other hand, due to the hygroscopic nature of the $\mathrm{K}_{2}(\mathrm{La}, \mathrm{Pr}) \mathrm{Cl}_{5}$ compounds, the contamination of the surface of the single crystals may result additional lines in the spectra, too. In addition to the electric or magnetic dipole induced transitions, usually weak and rather broad as well as diffuse lines of vibronic origin are frequently observed in the spectra of the $\mathrm{R}^{3+}$ ions, even for the $\mathrm{Pr}^{3+}$ ion [45-47]. For the $\mathrm{K}_{2}(\mathrm{La}, \mathrm{Pr}) \mathrm{Cl}_{5}$ samples studied, however, this kind of transitions were extremely weak and almost undetected. They were found only with the ${ }^{3} \mathrm{P}_{0} \rightarrow{ }^{3} \mathrm{~F}_{2}$ band in emission (Fig. 6a).

The absorption spectra of $\mathrm{K}_{2}(\mathrm{La}, \mathrm{Pr}) \mathrm{Cl}_{5}$ between 435 and $2000 \mathrm{~nm}\left(23,000\right.$ and $\left.5000 \mathrm{~cm}^{-1}\right)$ comprises of transitions from the ground ${ }^{3} \mathrm{H}_{4}$ level to the excited ${ }^{3} \mathrm{~F}_{2-4},{ }^{1} \mathrm{G}_{4}$, ${ }^{1} \mathrm{D}_{2},{ }^{3} \mathrm{P}_{0-2}$, and ${ }^{1} \mathrm{I}_{6}$ levels (Fig. 3 ). With increasing temperature the interpretation of the absorption spectra of $\mathrm{K}_{2}(\mathrm{La}, \mathrm{Pr}) \mathrm{Cl}_{5}$ was made more difficult since the higher Stark components of the ${ }^{3} \mathrm{H}_{4}$ level became thermally populated adding to the complexity of the spectra not only supplementary lines but also the increased homogeneous width of the lines. However, based on the splitting of the ${ }^{3} \mathrm{H}_{4}$ ground level obtained from the emission spectra recorded at $4 \mathrm{~K}$ with $\mathrm{Ar}^{+}$ion laser $(457.9 \mathrm{~nm})$ excitation, analysis of the c.f. Stark components of the higher ${ }^{2 S+1} \mathrm{~L}_{J}$ levels of the $\operatorname{Pr}^{3+}$ ion in absorption was possible. Assuming the mechanism of cooperative absorption $\left({ }^{3} \mathrm{H}_{4} \rightarrow{ }^{3} \mathrm{P}_{0}\right.$ (ion 1$)+{ }^{3} \mathrm{H}_{4(0-8)}$ (ion 2)) observed earlier in other polymeric or dimeric systems [47-49] the pair components can be selected and the remaining lines correspond to the transitions to the real Stark components of the respective excited levels. Although for $\mathrm{Pr}^{3+}$ in the chloroelpasolite host some anomalies in assignment of the ${ }^{1} \mathrm{D}_{2}$ and ${ }^{1} \mathrm{G}_{4}$ Stark levels have been reported, in this crystal mainly vibronic components are observed $\left(\mathrm{O}_{\mathrm{h}}\right.$ symmetry $)$ and it is very difficult to find electronic states, whereas in the $\mathrm{K}_{2} \mathrm{RCl}_{5}$ case this problem was not observed. The cooperative absorption can explain the drastic differences between the emission and absorption spectra at $4 \mathrm{~K}$. Since the ${ }^{3} \mathrm{P}_{0}$ level is unsplit by the c.f. effect, excitation with the narrow laser lines above the ${ }^{3} \mathrm{P}_{0}$ level leads to a simple, well resolved ${ }^{3} \mathrm{P}_{0}$ emission to lower levels [26]. On the other hand, the absorption spectra of $\mathrm{K}_{2} \mathrm{PrCl}_{5}$ at $4 \mathrm{~K}$ are complex as a result of the excitation of pairs of the $\mathrm{Pr}^{3+}$ ions [26]. Finally, close to all c.f. components of the excited ${ }^{3} \mathrm{~F}_{J}(J=2-4),{ }^{1} \mathrm{D}_{2},{ }^{1} \mathrm{G}_{4},{ }^{1} \mathrm{I}_{6}$, and ${ }^{3} \mathrm{P}_{J}(J=0$ 2) levels could be found from the different absorption spectra except for the ${ }^{1} \mathrm{I}_{6}$ level (Table 1 ). In addition, the energy of the ${ }^{1} \mathrm{~S}_{0}$ level could be detected by using the UV-VUV excitation spectra with synchrotron radiation as described above.

\subsection{Analysis of luminescence spectra}

The $\mathrm{Ar}^{+}$ion laser line at $457.9 \mathrm{~nm}$ excites very effectively the ${ }^{3} \mathrm{P}_{1}\left(\right.$ or $\left.{ }^{1} \mathrm{I}_{6}\right)$ level of the $\mathrm{Pr}^{3+}$ ion in the $\mathrm{K}_{2} \mathrm{LaCl}_{5}$ host. At low temperature the excitation energy relaxes in two ways; first, radiatively as luminescence from the ${ }^{3} \mathrm{P}_{0}$ level and second, non-radiatively, e.g. by multiphonon de-excitation or cross-relaxation, to the ${ }^{1} \mathrm{D}_{2}$ level which may luminescence, too. Additionally, the luminescence at the ambient temperature may consist of transitions from the ${ }^{3} \mathrm{P}_{1}$ level being thermally populated, as well. In the wavelength range between 435 and $1500 \mathrm{~nm}$ the luminescence spectrum of $\mathrm{Pr}^{3+}$ in the $\mathrm{K}_{2} \mathrm{LaCl}_{5}$ host matrix originates from the ${ }^{3} \mathrm{P}_{0} \rightarrow{ }^{3} \mathrm{H}_{4,5,6}$ and ${ }^{3} \mathrm{P}_{0} \rightarrow{ }^{3} \mathrm{~F}_{2,3,4}$ transitions from which the ${ }^{3} \mathrm{P}_{0} \rightarrow{ }^{3} \mathrm{H}_{4}$ and ${ }^{3} \mathrm{P}_{0} \rightarrow{ }^{3} \mathrm{~F}_{2}$ transitions dominate (Fig. 6b). In the range of $900-1500 \mathrm{~nm}$ the ${ }^{1} \mathrm{G}_{4} \rightarrow{ }^{3} \mathrm{H}_{5},{ }^{3} \mathrm{P}_{0} \rightarrow{ }^{1} \mathrm{G}_{4}$, ${ }^{1} \mathrm{I}_{6} \rightarrow{ }^{1} \mathrm{G}_{4}$ transitions were recorded as well as the ${ }^{1} \mathrm{D}_{2} \rightarrow{ }^{1} \mathrm{G}_{4}$ one which is not very common. This is in accordance to the observation that the electric dipole interaction is the main contribution responsible for the transitions in the $\operatorname{Pr}^{3+}$ luminescence spectrum. Very weak emission from the ${ }^{1} \mathrm{D}_{2}$ level was observed in addition to the ${ }^{3} \mathrm{P}_{0}$ emission in diluted crystals at 2 and $5 \mathrm{~mol} \%$ concentration. In general, the ${ }^{1} D_{2}$ emission slightly quenches when the sample temperature is increased probably due to the enhanced availability of lattice phonons for the de-excitation of the ${ }^{1} \mathrm{D}_{2}$ level. It is not the case here because of low energy of phonons. Otherwise the temperature dependency of the $\mathrm{Pr}^{3+}$ luminescence in $\mathrm{K}_{2}(\mathrm{La}, \mathrm{Pr}) \mathrm{Cl}_{5}$ is weak.

The concentration quenching of the ${ }^{3} \mathrm{P}_{0}$ emission was rather weak in $\mathrm{K}_{2}(\mathrm{La}, \mathrm{Pr}) \mathrm{Cl}_{5}$ since luminescence could be observed without difficulty even from a non-doped 

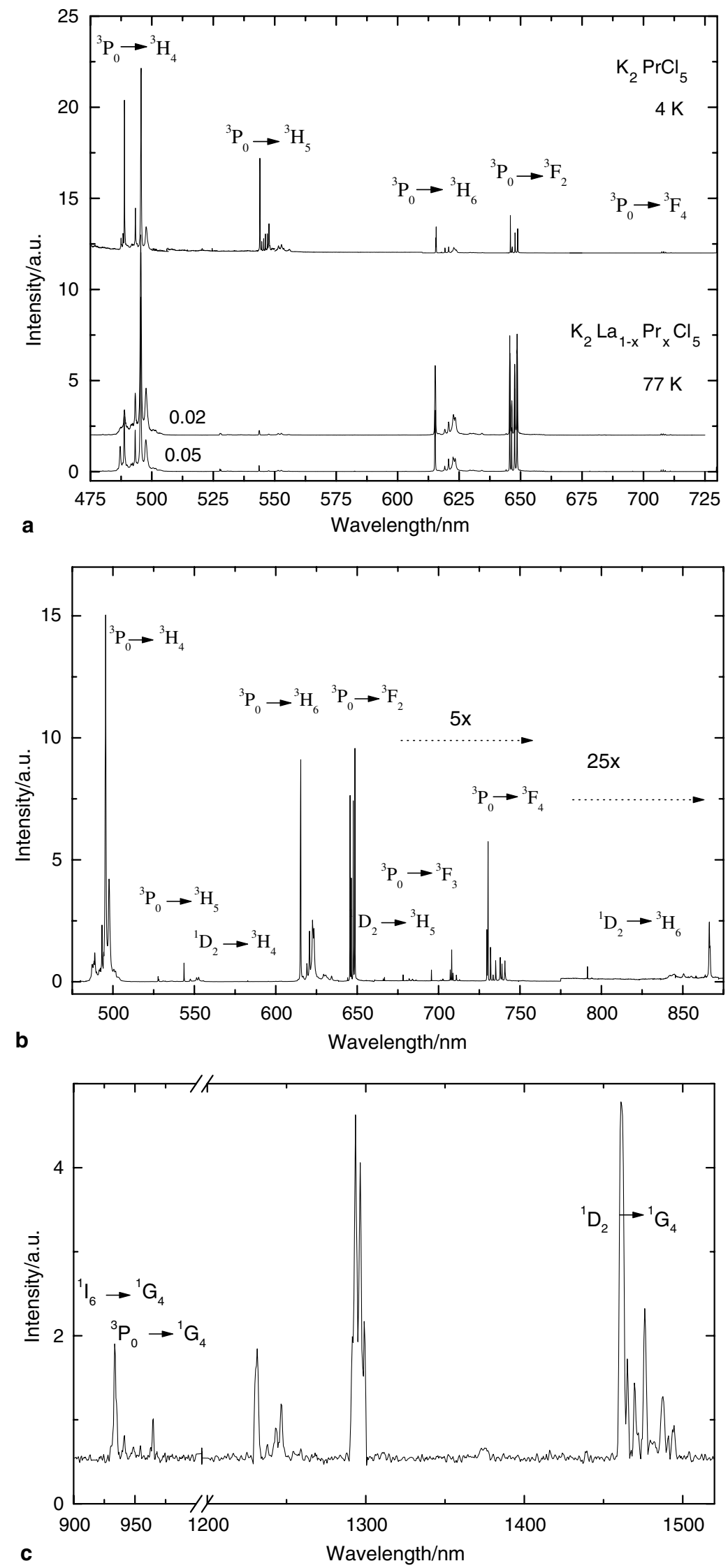

Fig. 6. The emission spectra of $\mathrm{K}_{2}\left(\mathrm{La}_{0.95} \mathrm{Pr}_{0.05}\right) \mathrm{Cl}_{5}, \mathrm{~K}_{2}\left(\mathrm{La}_{0.98} \mathrm{Pr}_{0.02}\right) \mathrm{Cl}_{5}$ single crystals and $\mathrm{K}_{2} \mathrm{PrCl}_{5}$ powder measured under Ar ${ }^{+}$ion laser excitation $\left(\lambda_{\text {exc }}=457.9 \mathrm{~nm}\right)$ at 77 and $4 \mathrm{~K}$. 
Table 1

Calculated (for $C_{2 \mathrm{v}}$ symmetry) and experimental energy levels schemes for $\operatorname{Pr}^{3+}$ in $\mathrm{K}_{2}(\mathrm{La}, \mathrm{Pr}) \mathrm{Cl}_{5}$

\begin{tabular}{|c|c|c|c|c|c|}
\hline \multirow[t]{2}{*}{${ }^{2 S+1} \mathrm{~L}_{J}^{\mathrm{a}}$} & & \multicolumn{3}{|c|}{ Energy level $\left(\mathrm{cm}^{-1}\right)$} & \multirow[t]{2}{*}{ Main ${ }^{2 S+1} \mathrm{~L}_{J M}$ components } \\
\hline & & Calc. $^{\mathrm{b}}$ & Exp. & $\overline{\text { Diff. }}$ & \\
\hline$\overline{{ }^{3} \mathrm{H}_{4}}$ & $\begin{array}{l}\mathrm{B}_{2} \\
\mathrm{~B}_{1} \\
\mathrm{~A}_{1} \\
\mathrm{~A}_{2} \\
\mathrm{~A}_{1} \\
\mathrm{~B}_{1} \\
\mathrm{~A}_{2} \\
\mathrm{~A}_{1} \\
\mathrm{~B}_{2}\end{array}$ & $\begin{array}{r}16 \\
34 \\
49 \\
130 \\
181 \\
251 \\
332 \\
421 \\
467\end{array}$ & $\begin{array}{r}0 \\
34 \\
57 \\
129 \\
201 \\
243 \\
337 \\
420 \\
458\end{array}$ & $\begin{array}{r}16 \\
0 \\
-8 \\
1 \\
-20 \\
8 \\
-5 \\
1 \\
9\end{array}$ & $\begin{array}{l}-0.689^{3} \mathrm{H}_{43}+0.689^{3} \mathrm{H}_{4-3}-0.113{ }^{1} \mathrm{G}_{43} \\
0.662^{3} \mathrm{H}_{43}+0.662{ }^{3} \mathrm{H}_{4-3}+0.215^{3} \mathrm{H}_{41} \\
-0.540^{3} \mathrm{H}_{42}-0.540^{3} \mathrm{H}_{4-2}+0.404^{3} \mathrm{H}_{44} \\
-0.677^{3} \mathrm{H}_{44}+0.6777^{3} \mathrm{H}_{4-4}+0.161^{3} \mathrm{H}_{42} \\
-0.559^{3} \mathrm{H}_{44}-0.559^{3} \mathrm{H}_{4-4}-0.343^{3} \mathrm{H}_{42} \\
-0.660^{3} \mathrm{H}_{41}-0.660^{3} \mathrm{H}_{4-1}+0.213^{3} \mathrm{H}_{43} \\
0.675^{3} \mathrm{H}_{42}-0.675^{3} \mathrm{H}_{4-2}+0.162^{3} \mathrm{H}_{44} \\
-0.895^{3} \mathrm{H}_{40}+0.275^{3} \mathrm{H}_{42}+0.275^{3} \mathrm{H}_{4-2} \\
0.688^{3} \mathrm{H}_{41}-0.688^{3} \mathrm{H}_{4-1}+0.115^{1} \mathrm{G}_{41}\end{array}$ \\
\hline${ }^{3} \mathrm{H}_{5}$ & $\begin{array}{l}\mathrm{A}_{2} \\
\mathrm{~A}_{1} \\
\mathrm{~B}_{2} \\
\mathrm{~B}_{1} \\
\mathrm{~B}_{2} \\
\mathrm{~A}_{2} \\
\mathrm{~B}_{1} \\
\mathrm{~B}_{2} \\
\mathrm{~A}_{1} \\
\mathrm{~A}_{2} \\
\mathrm{~B}_{1}\end{array}$ & $\begin{array}{l}2131 \\
2136 \\
2162 \\
2180 \\
2239 \\
2242 \\
2275 \\
2377 \\
2421 \\
2506 \\
2519\end{array}$ & $\begin{array}{l}2122 \\
2130 \\
2155 \\
2181 \\
2205 \\
2231 \\
2253 \\
2381 \\
2426 \\
2517 \\
2531\end{array}$ & $\begin{array}{r}9 \\
6 \\
7 \\
-1 \\
34 \\
11 \\
22 \\
-4 \\
-5 \\
-11 \\
-12\end{array}$ & $\begin{array}{l}-0.700^{3} \mathrm{H}_{54}-0.700^{3} \mathrm{H}_{5-4}-0.103^{3} \mathrm{H}_{50} \\
0.704{ }^{3} \mathrm{H}_{54}-0.704{ }^{3} \mathrm{H}_{5-4}-0.033{ }^{3} \mathrm{H}_{40} \\
-0.4866^{3} \mathrm{H}_{53}-0.4866^{3} \mathrm{H}_{5-3}+0.4377^{3} \mathrm{H}_{55} \\
0.601{ }^{3} \mathrm{H}_{55}-0.601{ }^{3} \mathrm{H}_{5-5}-0.366^{3} \mathrm{H}_{53} \\
0.5377^{3} \mathrm{H}_{55}+0.5377^{3} \mathrm{H}_{5-5}+0.353{ }^{3} \mathrm{H}_{51} \\
0.620{ }^{3} \mathrm{H}_{52}+0.620{ }^{3} \mathrm{H}_{5-2}+0.475^{3} \mathrm{H}_{50} \\
-0.598^{3} \mathrm{H}_{53}+0.598^{3} \mathrm{H}_{5-3}-0.368^{3} \mathrm{H}_{55} \\
-0.546^{3} \mathrm{H}_{51}-0.546^{3} \mathrm{H}_{5-1}+0.420{ }^{3} \mathrm{H}_{53} \\
0.703{ }^{3} \mathrm{H}_{52}-0.703{ }^{3} \mathrm{H}_{5-2}-0.038^{3} \mathrm{H}_{40} \\
-0.871{ }^{3} \mathrm{H}_{50}+0.332^{3} \mathrm{H}_{52}+0.332^{3} \mathrm{H}_{5-2} \\
0.704^{3} \mathrm{H}_{51}-0.704^{3} \mathrm{H}_{5-1}+0.049^{3} \mathrm{H}_{53}\end{array}$ \\
\hline${ }^{3} \mathrm{H}_{6}$ & $\begin{array}{l}\mathrm{B}_{1} \\
\mathrm{~B}_{2} \\
\mathrm{~A}_{1} \\
\mathrm{~A}_{2} \\
\mathrm{~B}_{1} \\
\mathrm{~A}_{1} \\
\mathrm{~A}_{1} \\
\mathrm{~A}_{2} \\
\mathrm{~B}_{2} \\
\mathrm{~B}_{1} \\
\mathrm{~A}_{2} \\
\mathrm{~A}_{1} \\
\mathrm{~B}_{2}\end{array}$ & $\begin{array}{l}4241 \\
4246 \\
4306 \\
4327 \\
4377 \\
4399 \\
4444 \\
4446 \\
4475 \\
4637 \\
4666 \\
4705 \\
4720\end{array}$ & $\begin{array}{l}4261 \\
4265 \\
4321 \\
4329 \\
4364 \\
4403 \\
4440 \\
4457 \\
4483 \\
4629 \\
4662 \\
4682 \\
4750\end{array}$ & $\begin{array}{r}-20 \\
-19 \\
-15 \\
-2 \\
13 \\
-4 \\
4 \\
-11 \\
-8 \\
8 \\
4 \\
23 \\
-30\end{array}$ & 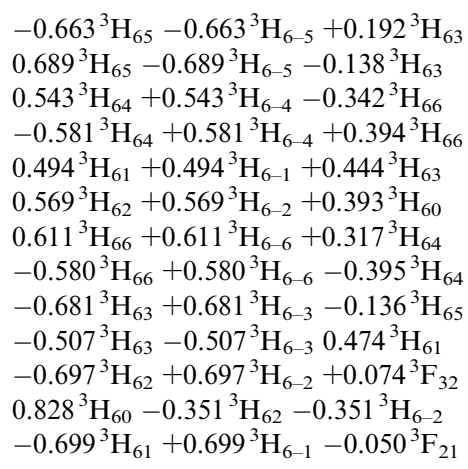 \\
\hline${ }^{3} \mathrm{~F}_{2}$ & $\begin{array}{l}\mathrm{A}_{1} \\
\mathrm{~B}_{1} \\
\mathrm{~B}_{2} \\
\mathrm{~A}_{1} \\
\mathrm{~A}_{2}\end{array}$ & $\begin{array}{l}5008 \\
5013 \\
5017 \\
5085 \\
5107\end{array}$ & $\begin{array}{l}5001 \\
5039 \\
5054 \\
5083 \\
5109\end{array}$ & $\begin{array}{r}7 \\
-26 \\
-37 \\
2 \\
-2\end{array}$ & $\begin{array}{l}0.922^{3} \mathrm{~F}_{20}-0.226^{3} \mathrm{~F}_{22}-0.226^{3} \mathrm{~F}_{2-2} \\
0.692^{3} \mathrm{~F}_{21}+0.692^{3} \mathrm{~F}_{2-1}+0.103^{1} \mathrm{D}_{21} \\
-0.687^{3} \mathrm{~F}_{21}+0.687^{3} \mathrm{~F}_{2-1}-0.107^{1} \mathrm{D}_{21} \\
-0.649^{3} \mathrm{~F}_{22}-0.649^{3} \mathrm{~F}_{2-2}-0.311^{3} \mathrm{~F}_{20} \\
-0.695^{3} \mathrm{~F}_{22}+0.695^{3} \mathrm{~F}_{2-2}-0.108^{1} \mathrm{D}_{22}\end{array}$ \\
\hline${ }^{3} \mathrm{~F}_{3}$ & $\begin{array}{l}\mathrm{B}_{1} \\
\mathrm{~B}_{2} \\
\mathrm{~A}_{1} \\
\mathrm{~A}_{2} \\
\mathrm{~A}_{2} \\
\mathrm{~B}_{2} \\
\mathrm{~B}_{1}\end{array}$ & $\begin{array}{l}6369 \\
6377 \\
6417 \\
6420 \\
6459 \\
6467 \\
6488\end{array}$ & $\begin{array}{l}6340 \\
6386 \\
6399 \\
6420 \\
6452 \\
6461 \\
6499\end{array}$ & $\begin{array}{r}29 \\
-9 \\
18 \\
0 \\
7 \\
6 \\
-11\end{array}$ & $\begin{array}{l}0.655^{3} \mathrm{~F}_{31}-0.655^{3} \mathrm{~F}_{3-1}-0.239^{3} \mathrm{~F}_{33} \\
-0.695^{3} \mathrm{~F}_{31}-0.695^{3} \mathrm{~F}_{3-1}-0.089^{3} \mathrm{~F}_{33} \\
0.699^{3} \mathrm{~F}_{32}-0.699^{3} \mathrm{~F}_{3-2}-0.051^{3} \mathrm{~F}_{42} \\
-0.953^{3} \mathrm{~F}_{30}+0.200^{3} \mathrm{~F}_{32}+0.200^{3} \mathrm{~F}_{3-2} \\
-0.669^{3} \mathrm{~F}_{32}-0.669^{3} \mathrm{~F}_{3-2}-0.288^{3} \mathrm{~F}_{30} \\
0.688^{3} \mathrm{~F}_{33}+0.688^{3} \mathrm{~F}_{3-3}-0.101{ }^{3} \mathrm{~F}_{31} \\
-0.651^{3} \mathrm{~F}_{33}+0.651^{3} \mathrm{~F}_{3-3}-0.251^{3} \mathrm{~F}_{31}\end{array}$ \\
\hline${ }^{3} \mathrm{~F}_{4}$ & $\begin{array}{l}\mathrm{A}_{1} \\
\mathrm{~B}_{2} \\
\mathrm{~B}_{1} \\
\mathrm{~A}_{2} \\
\mathrm{~B}_{1} \\
\mathrm{~A}_{1} \\
\mathrm{~B}_{2} \\
\mathrm{~A}_{2} \\
\mathrm{~A}_{1}\end{array}$ & $\begin{array}{l}6787 \\
6839 \\
6841 \\
6862 \\
6895 \\
6905 \\
6995 \\
7017 \\
7037\end{array}$ & $\begin{array}{l}6815 \\
6825 \\
6830 \\
6863 \\
6885 \\
6923 \\
6975 \\
6994 \\
7026\end{array}$ & $\begin{array}{r}-28 \\
14 \\
11 \\
-1 \\
10 \\
-18 \\
20 \\
23 \\
11\end{array}$ & $\begin{array}{l}-0.534^{3} \mathrm{~F}_{42}-0.534^{3} \mathrm{~F}_{4-2}+0.405^{1} \mathrm{G}_{42} \\
0.469^{3} \mathrm{~F}_{43}-0.469^{3} \mathrm{~F}_{4-3}-0.349{ }^{1} \mathrm{G}_{43} \\
0.450{ }^{3} \mathrm{~F}_{43}+0.450{ }^{3} \mathrm{~F}_{4-3}-0.340{ }^{1} \mathrm{G}_{43} \\
-0.478^{3} \mathrm{~F}_{42}+0.478^{3} \mathrm{~F}_{4-2}+0.363{ }^{1} \mathrm{G}_{42} \\
0.473^{3} \mathrm{~F}_{41}+0.473{ }^{3} \mathrm{~F}_{4-1}-0.332{ }^{1} \mathrm{G}_{41} \\
0.661{ }^{3} \mathrm{~F}_{40}-0.454{ }^{1} \mathrm{G}_{40}+0.322^{3} \mathrm{~F}_{44} \\
-0.498^{3} \mathrm{~F}_{41}+0.498^{3} \mathrm{~F}_{4-1}+0.326^{1} \mathrm{G}_{41} \\
0.493{ }^{3} \mathrm{~F}_{44}-0.493{ }^{3} \mathrm{~F}_{4-4}-0.351^{1} \mathrm{G}_{44} \\
0.493{ }^{3} \mathrm{~F}_{40}-0.444^{3} \mathrm{~F}_{44}-0.444^{3} \mathrm{~F}_{4-4}\end{array}$ \\
\hline${ }^{1} \mathrm{G}_{4}$ & $\begin{array}{l}\mathrm{A}_{1} \\
\mathrm{~A}_{2} \\
\mathrm{~B}_{1} \\
\mathrm{~B}_{2} \\
\mathrm{~A}_{1}\end{array}$ & $\begin{array}{l}9645 \\
9696 \\
9718 \\
9741 \\
9809\end{array}$ & $\begin{array}{l}9645 \\
9698\end{array}$ & $\begin{array}{r}0 \\
-2 \\
-11 \\
-5\end{array}$ & $\begin{array}{l}-0.529^{1} \mathrm{G}_{42}-0.529{ }^{1} \mathrm{G}_{4-2}-0.411^{3} \mathrm{~F}_{42} \\
0.477{ }^{1} \mathrm{G}_{42}-0.477{ }^{1} \mathrm{G}_{4-2}+0.372{ }^{3} \mathrm{~F}_{42} \\
0.506^{1} \mathrm{G}_{43}+0.506^{1} \mathrm{G}_{4-3}+0.390^{3} \mathrm{~F}_{43} \\
0.515^{1} \mathrm{G}_{43}-0.515^{1} \mathrm{G}_{4-3}+0.389^{3} \mathrm{~F}_{43} \\
-0.504^{1} \mathrm{G}_{40}-0.419^{1} \mathrm{G}_{44}-0.419^{1} \mathrm{G}_{4-4}\end{array}$ \\
\hline
\end{tabular}


Table 1 (continued)

\begin{tabular}{|c|c|c|c|c|c|}
\hline \multirow[t]{2}{*}{${ }^{2 S+1} \mathrm{~L}_{J}^{\mathrm{a}}$} & & \multicolumn{3}{|c|}{ Energy level $\left(\mathrm{cm}^{-1}\right)$} & \multirow[t]{2}{*}{ Main ${ }^{2 S+1} \mathrm{~L}_{J M}$ components } \\
\hline & & Calc. $^{\mathrm{b}}$ & Exp. & Diff. & \\
\hline & $\begin{array}{l}\mathrm{B}_{1} \\
\mathrm{~A}_{2} \\
\mathrm{~B}_{2} \\
\mathrm{~A}_{1}\end{array}$ & $\begin{array}{r}9838 \\
9980 \\
10,015 \\
10,140\end{array}$ & $\begin{array}{r}9833 \\
9980 \\
10,038 \\
10,140\end{array}$ & $\begin{array}{r}5 \\
0 \\
-23 \\
0\end{array}$ & $\begin{array}{l}-0.517^{1} \mathrm{G}_{41}-0.517^{1} \mathrm{G}_{4-1}-0.375^{3} \mathrm{~F}_{41} \\
0.489{ }^{1} \mathrm{G}_{44}-0.489{ }^{1} \mathrm{G}_{4-4}+0.356^{3} \mathrm{~F}_{44} \\
0.533^{1} \mathrm{G}_{41}-0.533{ }^{1} \mathrm{G}_{4-1}+0.362^{3} \mathrm{~F}_{41} \\
-0.646^{1} \mathrm{G}_{40}-0.415^{3} \mathrm{~F}_{40}+0.339^{1} \mathrm{G}_{44}\end{array}$ \\
\hline${ }^{1} \mathrm{D}_{2}$ & $\begin{array}{l}\mathrm{A}_{1} \\
\mathrm{~B}_{2} \\
\mathrm{~A}_{2} \\
\mathrm{~B}_{1} \\
\mathrm{~A}_{1}\end{array}$ & $\begin{array}{l}16,564 \\
16,712 \\
16,779 \\
16,980 \\
16,997\end{array}$ & $\begin{array}{l}16,570 \\
16,680 \\
16,807 \\
16,978 \\
17,021\end{array}$ & $\begin{array}{r}-6 \\
32 \\
-28 \\
2 \\
-24\end{array}$ & $\begin{array}{l}-0.942{ }^{1} \mathrm{D}_{20}+0.279^{3} \mathrm{P}_{20}+0.156{ }^{3} \mathrm{~F}_{20} \\
-0.667{ }^{1} \mathrm{D}_{21}+0.667{ }^{1} \mathrm{D}_{2-1}+0.206{ }^{3} \mathrm{P}_{21} \\
0.669{ }^{1} \mathrm{D}_{22}-0.669{ }^{1} \mathrm{D}_{2-2}-0.200{ }^{3} \mathrm{P}_{22} \\
-0.664{ }^{1} \mathrm{D}_{21}-0.664^{1} \mathrm{D}_{2-1}+0.218^{3} \mathrm{P}_{21} \\
0.66{ }^{1} \mathrm{D}_{22}+0.663{ }^{1} \mathrm{D}_{2-2}-0.212^{3} \mathrm{P}_{22}\end{array}$ \\
\hline${ }^{3} \mathrm{P}_{0}$ & $\mathrm{~A}_{1}$ & 20,498 & 20,530 & -32 & $0.991{ }^{3} \mathrm{P}_{00}+0.098{ }^{1} \mathrm{~S}_{00}-0.069^{3} \mathrm{P}_{20}$ \\
\hline${ }^{1} \mathrm{I}_{6}$ & $\begin{array}{l}\mathrm{A}_{1} \\
\mathrm{~A}_{2}\end{array}$ & $\begin{array}{l}20,844 \\
20,845\end{array}$ & $\begin{array}{l}20,827 \\
20,841\end{array}$ & $\begin{array}{r}17 \\
4\end{array}$ & $\begin{array}{l}0.686{ }^{1} \mathrm{I}_{66}+0.686{ }^{1} \mathrm{I}_{6-6}+0.163{ }^{1} \mathrm{I}_{6-4} \\
-0.688{ }^{1} \mathrm{I}_{66}+0.688{ }^{1} \mathrm{I}_{6-6}+0.159{ }^{1} \mathrm{I}_{6-4}\end{array}$ \\
\hline${ }^{3} \mathrm{P}_{1}$ & $\begin{array}{l}\mathrm{B}_{2} \\
\mathrm{~B}_{1} \\
\mathrm{~A}_{2}\end{array}$ & $\begin{array}{l}21,037 \\
21,101 \\
21,229\end{array}$ & $\begin{array}{l}21,070 \\
21,088 \\
21,221\end{array}$ & $\begin{array}{r}-33 \\
13 \\
8\end{array}$ & $\begin{array}{l}0.704^{3} \mathrm{P}_{11}+0.704^{3} \mathrm{P}_{1-1}+0.053^{3} \mathrm{P}_{21} \\
0.700{ }^{3} \mathrm{P}_{11}-0.700^{3} \mathrm{P}_{1-1}+0.088^{3} \mathrm{P}_{21} \\
0.997{ }^{3} \mathrm{P}_{10}-0.042^{3} \mathrm{P}_{22}+0.042{ }^{3} \mathrm{P}_{2-2}\end{array}$ \\
\hline${ }^{1} \mathrm{I}_{6}$ & $\begin{array}{l}\mathrm{B}_{1} \\
\mathrm{~B}_{2} \\
\mathrm{~A}_{2} \\
\mathrm{~B}_{2} \\
\mathrm{~A}_{1} \\
\mathrm{~B}_{1} \\
\mathrm{~A}_{1} \\
\mathrm{~A}_{2} \\
\mathrm{~B}_{1} \\
\mathrm{~B}_{2} \\
\mathrm{~A}_{1}\end{array}$ & $\begin{array}{l}21,246 \\
21,261 \\
21,346 \\
21,381 \\
21,384 \\
21,518 \\
21,569 \\
21,606 \\
21,639 \\
21,746 \\
21,750\end{array}$ & $\begin{array}{l}21,505 \\
21,598 \\
21,652 \\
21,738\end{array}$ & $\begin{array}{r}13 \\
8 \\
-13 \\
8\end{array}$ & $\begin{array}{l}-0.586{ }^{1} \mathrm{I}_{65}-0.586{ }^{1} \mathrm{I}_{6-5}-0.353{ }^{1} \mathrm{I}_{6-3} \\
0.564{ }^{1} \mathrm{I}_{65}-0.564{ }^{1} \mathrm{I}_{6-5}-0.397{ }^{1} \mathrm{I}_{6-3} \\
-0.629{ }^{1} \mathrm{I}_{62}+0.629{ }^{1} \mathrm{I}_{6-2}-0.309{ }^{1} \mathrm{I}_{64} \\
-0.566{ }^{1} \mathrm{I}_{61}+0.566{ }^{1} \mathrm{I}_{6-1}+0.330{ }^{1} \mathrm{I}_{65} \\
0.691{ }^{1} \mathrm{I}_{60}-0.455{ }^{1} \mathrm{I}_{64}-0.455{ }^{1} \mathrm{I}_{6-4} \\
0.653{ }^{1} \mathrm{I}_{61}+0.653{ }^{1} \mathrm{I}_{6-1}+0.251{ }^{1} \mathrm{I}_{65} \\
0.647{ }^{1} \mathrm{I}_{60}+0.448{ }^{1} \mathrm{I}_{62}+0.448{ }^{1} \mathrm{I}_{6-2} \\
0.614{ }^{1} \mathrm{I}_{64}-0.614{ }^{1} \mathrm{I}_{6-4}-0.320{ }^{1} \mathrm{I}_{62} \\
0.602{ }^{1} \mathrm{I}_{63}+0.602{ }^{1} \mathrm{I}_{6-3}-0.301{ }^{1} \mathrm{I}_{65} \\
0.522{ }^{1} \mathrm{I}_{63}-0.522{ }^{1} \mathrm{I}_{6-3}-0.395{ }^{1} \mathrm{I}_{61} \\
-0.508{ }^{1} \mathrm{I}_{62}-0.508{ }^{1} \mathrm{I}_{6-2}+0.426{ }^{1} \mathrm{I}_{64}\end{array}$ \\
\hline${ }^{3} \mathrm{P}_{2}$ & $\begin{array}{l}\mathrm{A}_{1} \\
\mathrm{~B}_{2} \\
\mathrm{~B}_{1} \\
\mathrm{~A}_{2} \\
\mathrm{~A}_{1}\end{array}$ & $\begin{array}{l}22,236 \\
22,276 \\
22,407 \\
22,441 \\
22,487\end{array}$ & $\begin{array}{l}22,222 \\
22,297 \\
22,396 \\
22,422 \\
22,472\end{array}$ & $\begin{array}{r}14 \\
-21 \\
11 \\
19 \\
15\end{array}$ & $\begin{array}{l}-0.942^{3} \mathrm{P}_{20}-0.278^{1} \mathrm{D}_{20}+0.111^{3} \mathrm{P}_{22} \\
0.673{ }^{3} \mathrm{P}_{21}-0.673{ }^{3} \mathrm{P}_{2-1}+0.205^{1} \mathrm{D}_{21} \\
0.664{ }^{3} \mathrm{P}_{21}+0.664^{3} \mathrm{P}_{2-1}+0.214{ }^{1} \mathrm{D}_{21} \\
-0.676^{3} \mathrm{P}_{22}+0.676^{3} \mathrm{P}_{2-2}-0.200{ }^{1} \mathrm{D}_{22} \\
0.661^{3} \mathrm{P}_{22}+0.661{ }^{3} \mathrm{P}_{2-2}+0.210^{1} \mathrm{D}_{22}\end{array}$ \\
\hline${ }^{1} \mathrm{~S}_{0}$ & $\mathrm{~A}_{1}$ & 46,773 & 46,773 & 0 & $-0.995{ }^{1} \mathrm{~S}_{00}+0.098{ }^{3} \mathrm{P}_{00}+0.008{ }^{1} \mathrm{D}_{20}$ \\
\hline
\end{tabular}

a Main free ion component quantum numbers for the level associated with the group.

b Calculated with the best fit set of free ion and crystal field parameters in Table 2 .

$\mathrm{K}_{2} \mathrm{PrCl}_{5}$ [26]. However, then in addition to the usual single ion emission, emission from the $\mathrm{Pr}^{3+}$ ion pairs could be observed. Note that in our case this effect is not very important.

A comparison of the $\mathrm{K}_{2} \mathrm{PrCl}_{5}$ spectra with those of the doped crystals was found helpful in the analysis, because the pair components become weaker with decreasing dopant concentration (Fig. 3).

As a function of the excitation means, i.e. with the $\mathrm{Ar}^{+}$ ion laser line at $457.9 \mathrm{~nm}$, the xenon lamp in the UV region, the excimer laser at $308 \mathrm{~nm}$, or the $\gamma$-radiation, there were found some fundamental differences in the luminescence spectra. The simplest spectra were obtained by using the $\mathrm{Ar}^{+}$ion laser excitation (Fig. 6). Only very weak emission was observed from the ${ }^{1} \mathrm{D}_{2}$ level even with the lowest $\left(x_{\mathrm{Pr}}=0.02\right)$ dopant concentration. The ${ }^{3} \mathrm{P}_{0}$ level is fed efficiently and emission is observed from this level. When the excimer laser excitation was used, in addition to the emission from the ${ }^{3} \mathrm{P}_{0}$ level, a broad band emission was also detected at $375 \mathrm{~nm}$ (Figs. 7a and b). The broad band emission is stronger at room temperature than the emission from the ${ }^{3} \mathrm{P}_{0}$ level but the reverse was observed at $77 \mathrm{~K}$. The origin of this emission is unknown at the moment but it may result from the annihilation of excitons. The possibility of self-trapped exciton emission has been considered for the $\mathrm{Ce}^{3+}$ doped $\mathrm{K}_{2} \mathrm{LaCl}_{5}[8]$ and for $\mathrm{Pr}^{3+}$ in $\mathrm{CsCdBr}_{3}$ [50].

The analysis of the luminescence spectra was facilitated by the almost complete absence of overlapping transitions. Only the ${ }^{3} \mathrm{P}_{0} \rightarrow{ }^{3} \mathrm{H}_{6}$ and ${ }^{1} \mathrm{D}_{2} \rightarrow{ }^{3} \mathrm{H}_{4}$ transitions situate at approximately the same range. But these transitions were well separated with 100 to $2 \mathrm{~mol} \%$ dilution of the $\mathrm{Pr}^{3+}$ concentration. The number of lines found for each transition is in accordance with the low $C_{\mathrm{s}}$ point symmetry of the $\operatorname{Pr}^{3+}$ site although some lines are weak. That was one of the reasons to relate the $\operatorname{Pr}^{3+}$ site symmetry to $C_{2 \mathrm{v}}$. The easy interpretation of electronic transitions was further facilitated by the almost absence of any vibronic structure. The analysis of the luminescence spectra of $\mathrm{K}_{2}(\mathrm{La}, \mathrm{Pr}) \mathrm{Cl}_{5}$ yielded all the Stark levels for the ${ }^{3} \mathrm{H}_{4,5,6}$ and ${ }^{3} \mathrm{~F}_{2,3,4}$ levels, in total 54 c.f. 

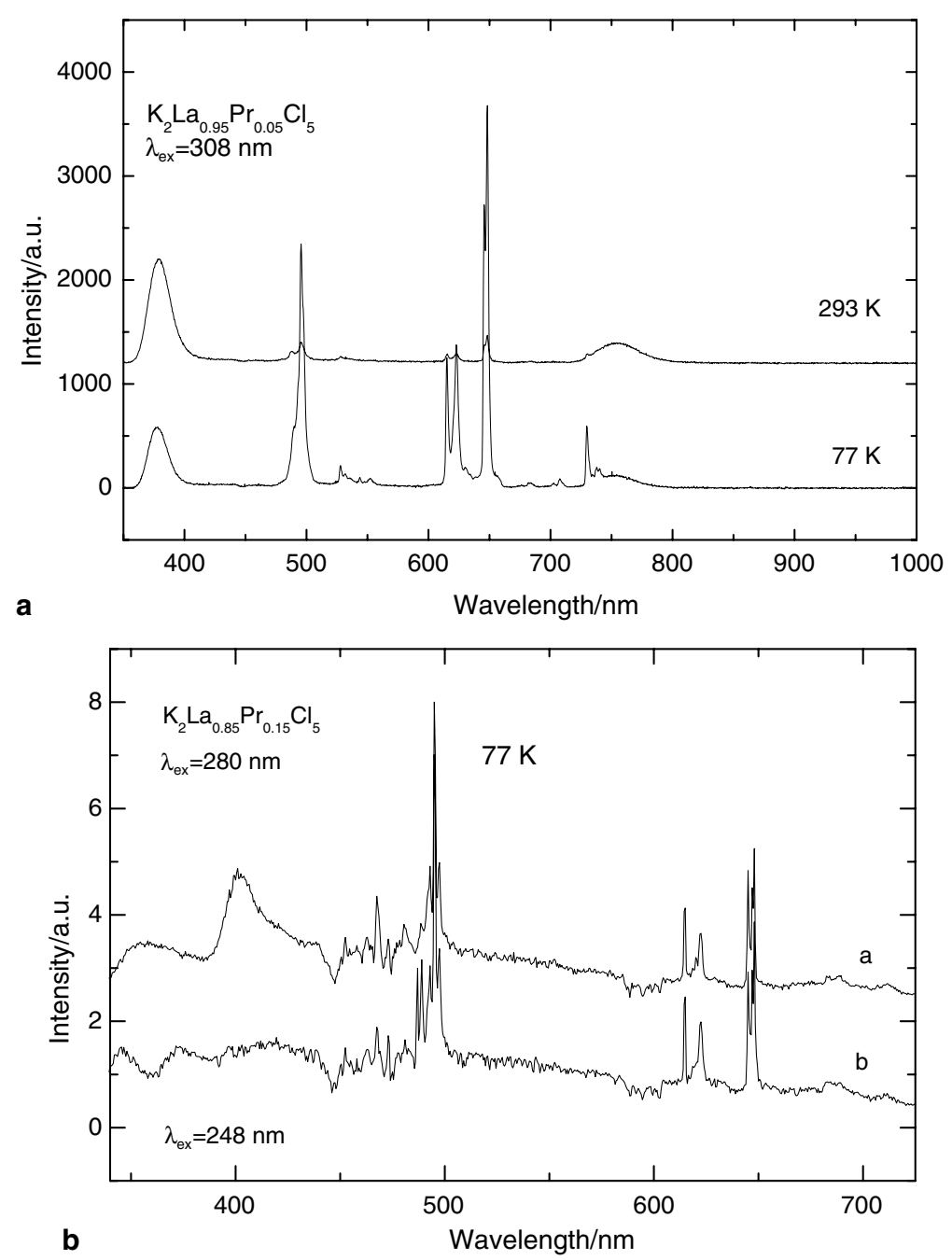

Fig. 7. Luminescence spectra of $\mathrm{K}_{2} \mathrm{La}_{0.85} \mathrm{Pr}_{0.15} \mathrm{Cl}_{5}$ and $\mathrm{K}_{2} \mathrm{La}_{0.95} \mathrm{Pr}_{0.05} \mathrm{Cl}_{5}$ crystals at 293 and $77 \mathrm{~K}$ excited by different lines: $308 \mathrm{~nm}(\mathrm{a}) ; 280 \mathrm{~nm}$ and $248 \mathrm{~nm}$ (b).

levels. Together with the levels deduced from the absorption spectra, almost all of the levels of the $4 \mathrm{f}^{2}$ electron configuration of the $\operatorname{Pr}^{3+}$ ion doped in $\mathrm{K}_{2} \mathrm{LaCl}_{5}$ were available for the energy level simulation to be carried out with the phenomenological model.

\subsection{Simulation of the $4 f^{2}$ energy level scheme in $K_{2} \mathrm{PrCl}_{5}$}

The exhaustive spectroscopic measurements involving the absorption, excitation, and emission spectra of different non-doped $\left(\mathrm{K}_{2} \mathrm{PrCl}_{5}\right)$ and doped $\mathrm{K}_{2}(\mathrm{La}, \mathrm{Pr}) \mathrm{Cl}_{5}$ samples with several $\mathrm{Pr}^{3+}$ concentrations gave a very good starting set of the c.f. energy levels since in total 86 out of the 91 c.f. levels were finally found and used in the calculations (Table 1). However, at the starting point of the c.f. simulation the number of well-resolved levels was only 65 . The 21 additional levels were found from the absorption and emission spectra with the aid of the interactive simulation process, i.e. with the original set of energy levels and the new set of parameters refined, it was possible to include more levels into the simulation. Accordingly, at the beginning of the fitting procedure only those levels which could be assigned unambiguously were included into the simulation. These levels included most of the Stark levels for the ${ }^{3} \mathrm{H}_{J}$ $(J=4,6),{ }^{3} \mathrm{P}_{J}(J=0-2),{ }^{3} \mathrm{~F}_{J}(J=2-4)$ and ${ }^{1} \mathrm{D}_{2}$ levels. At this step the set consisting of the electron repulsion parameters $\left(F^{2}, F^{4}, F^{6}\right)$, the spin-orbit coupling constant $\zeta_{4 \mathrm{f}}$ and the nine c.f. parameters was adjusted. The additional energy levels were included into the fit and the remaining free ion parameters $(\alpha, \beta$, and $\gamma)$ were varied as the iteration procedure proceeded. Despite of the high number of experimental levels used in the simulation it was not possible to label an irreducible representation for appropriate c.f. levels because the spectra in polarized radiation are not available. Therefore, each experimental level was assigned to a calculated one, closest in the energy. It should be noted that the $\operatorname{Pr}^{3+}$ energy level set obtained in the present work is substantially different from the one reported previously [26].

The final simulation was carried out in a way that both the free ion and the c.f. contributions were treated simultaneously. The unrestricted variation of the $\gamma$ parameter 
which usually proves to be a serious problem leading to unrealistic values for this parameter was carried out successfully since the position of the ${ }^{1} \mathrm{~S}_{0}$ level was known. The entire $4 \mathrm{f}^{2}$ basis set of the 91 c.f. levels was used in the simulation and no truncation of the wave function set was employed. It should be noted that the set of 86 levels out of 91 is very large and this is reflected in the high quality and reliability of the simulation as well as in the low esd's of all the parameters.

The free ion and c.f. parameters of the phenomenological Hamiltonian (Eqs. (1) and (2)) were determined by minimizing the difference between the energies of the experimental and calculated c.f. levels with the aid of standard least squares calculations. The goodness of the simulation can be judged by the root mean square (rms) deviation value which is defined as follows:

$\sigma=\left[\frac{\sum_{i=1}^{N}\left(E_{\text {exp. }}(i)-E_{\text {calc. }}(i)\right)^{2}}{(N-P)}\right]^{1 / 2}$

where $N(=86)$ and $P(=17)$ are the number of experimental levels and parameters to be varied freely, respectively.

The initial values for the free-ion parameters were taken from those used for the simulation of the $4 \mathrm{f}^{2}$ energy level scheme in $\mathrm{PrOCl}$ [45]. These free ion parameters were modified prior to the refinements in order to yield a good fit to the approximate barycenters of the ${ }^{2 S+1} \mathrm{~L}_{J}$ levels deduced from the absorption and emission spectra. In this optimization, not all c.f. components were available to be included into the calculation of the barycenters, however.

The judicious choice of the initial c.f. parameter set is the crucial step in the c.f. simulation involving any $\mathrm{R}^{3+}$ ion in a low symmetry site. In such a case, it is evident that several sets of c.f. parameters will give fits of the same quality to the experimental levels, i.e. with a similar rms deviation. Thus physically meaningless simulations may arise. In order to avoid such a danger, special attention was paid on the good choice of the starting set of the c.f. parameters.

It is well known that some levels are more sensitive to changes in certain parameters than to changes in the others. The most simple case is the ${ }^{7} \mathrm{~F}_{J}(J=0-6)$ multiplet within the $4 \mathrm{f}^{6}$ electron configuration of the $\mathrm{Eu}^{3+}$ ion. The second rank c.f. parameters $B_{0}^{2}$ and $B_{2}^{2}$ define exclusively the c.f. splitting of the ${ }^{7} \mathrm{~F}_{1}$ free ion level, the fourth rank c.f. parameters $B_{q}^{4}(q=0,2,3,4)$ define the c.f. splitting of the ${ }^{7} \mathrm{~F}_{2}$ free-ion level (the $\mathrm{B}_{q}^{2}$ parameters were determined from the splitting of the ${ }^{7} F_{1}$ level and can be kept constant in further calculations) and when these parameters are fixed one gets the sixth rank c.f. parameters $B_{q_{7}}^{6}(q=0,2,3,4,6)$ from the analysis of the c.f. splitting of the ${ }^{q_{7}} \mathrm{~F}_{3-6}$ free-ion levels. In general, the 2nd, 4th, and 6th rank parameters can be defined phenomenologically by the c.f. splitting of the ${ }^{2 S+1} \mathrm{~L}_{J}$ levels with $J \geqslant 1, J \geqslant 2$, and $J \geqslant 3$, respectively. However, one should be careful since this simple rule is not always valid. More theoretically, the corresponding reduced matrix elements should be zero (or close to it) before the effect of the parameters comes negligible.
Fortunately to the c.f. simulation of the energy level scheme of the $\mathrm{Pr}^{3+}$ ion in $\mathrm{K}_{2}(\mathrm{La}, \mathrm{Pr}) \mathrm{Cl}_{5}$, the corresponding data for the $\mathrm{K}_{2} \mathrm{EuCl}_{5}$ compound with the same stoichiometry and structure, was available - but only partly [14]. Despite the rather bold speculation presented in this paper on the existence of a higher than $C_{\mathrm{s}}$ point symmetry for the $\mathrm{Eu}^{3+}$ site, the data on the c.f. splitting of the ${ }^{7} \mathrm{~F}_{1}$ and ${ }^{7} \mathrm{~F}_{2}$ free ion levels seems reliable. The reliability of the data can be improved with the use of the present knowledge on the barycenters of the levels which helps to find the missing c.f. level(s) [51,52]. Accordingly, the magnitude of the $B_{0}^{2}$ and $B_{2}^{2}$ parameters could easily be deduced from the data on $\mathrm{K}_{2} \mathrm{EuCl}_{5}$ especially since there exists a linear correlation between the c.f. splitting of the ${ }^{7} F_{1}$ free-ion level and the 2nd rank parameters [23]. However, the easy acquirement of these parameter values is true only if a higher than $C_{\mathrm{s}}$ point symmetry exists in $\mathrm{K}_{2} \mathrm{EuCl}_{5}$, i.e. the value of the $B_{2}^{2}$ parameter is small. The structural data gives no direct support to this idea, however, as stated above.

In order to solve this puzzle additional information is needed. Even if the conventional wisdom can tell that the Extended Electrostatic Point Charge Model calculations do not give accurate results, the ratios between the same rank parameters may be considered approximately correct. The PCEM calculations carried out for $\mathrm{K}_{2} \mathrm{PrCl}_{5}$ showed that the $B_{0}^{2}$ parameter value is significantly larger than that of $B_{2}^{2}$, i.e. 265 versus $127 \mathrm{~cm}^{-1}$. Of equal importance is the observation that both parameters are positive. The results of the PCEM calculations are in fair agreement with the deductions made from the splitting of the ${ }^{7} F_{1}$ free ion level in $\mathrm{K}_{2} \mathrm{EuCl}_{5}$ which gave the following approximate $B_{0}^{2}$ and $B_{2}^{2}$ parameter values: 450 and $50 \mathrm{~cm}^{-1}$. It should be noted that the PCEM ratio between these two parameters is not respected.

The crystal field splitting of the ${ }^{7} \mathrm{~F}_{2}$ free-ion level in $\mathrm{K}_{2} \mathrm{EuCl}_{5}$ gave in a rather straightforward manner good approximations for the $B_{0}^{4}, B_{2}^{4}$, and $B_{4}^{4}$ parameter values. Since the $\mathrm{Pr}^{3+}$ ion is larger than the $\mathrm{Eu}^{3+}$ one, it is expected that the crystal field is gaining strength from the $\mathrm{K}_{2} \mathrm{EuCl}_{5}$ to the $\mathrm{K}_{2} \mathrm{PrCl}_{5}$ host [43] and the individual c.f. parameter values should then be higher, too [52]. No attempt to get even approximate values for the 6th rank parameters for $\mathrm{K}_{2} \mathrm{PrCl}_{5}$ with the data for $\mathrm{K}_{2} \mathrm{EuCl}_{5}$ was made since the data available was not complete enough.

For the $\mathrm{K}_{2} \mathrm{LaCl}_{5}$ host, it was found that the general correlation between the c.f. splittings and the rank of the c.f. parameters was valid for the ${ }^{3} \mathrm{P}_{1}$ as well as for the ${ }^{3} \mathrm{P}_{2}$ and ${ }^{1} \mathrm{D}_{2}$ levels while the c.f. splitting of the ${ }^{3} \mathrm{~F}_{2}$ level was defined not only by the 2 nd and 4 th rank parameters, respectively, but also by the 6th rank ones. In conclusion, the values for the 2 nd and 4 th rank parameters could be obtained unambiguously with the combination of the data for $\mathrm{K}_{2} \mathrm{EuCl}_{5}$ and $\mathrm{K}_{2}(\mathrm{La}, \mathrm{Pr}) \mathrm{Cl}_{5}$ as well as with the aid of the PCEM calculations. From the PCEM calculations, it was found that the 6th rank parameters should assume rather low values and, indeed, the c.f. splittings of the ${ }^{2 S+1} \mathrm{~L}_{J}$ levels with $J \geqslant 3$ in $\mathrm{K}_{2} \mathrm{PrCl}_{5}$ were largely defined by the 2 nd 
and 4th rank parameters. The 6th rank parameters were obtained without any difficulties after initial manual optimization. Since the number of the c.f. splittings affected by the 6th rank parameters is quite large, i.e. the ${ }^{3} \mathrm{H}_{J}$ $(J=4-6),{ }^{3} \mathrm{~F}_{J}(J=3,4),{ }^{1} \mathrm{I}_{6}$, and ${ }^{1} \mathrm{G}_{4}$ levels, the reliability of the parameter values can be considered as very good. Especially so since more than 20 levels could be found during the intermediate steps in the simulation process as weak lines in the spectra.

All the adjusted parameters achieved stable values at the end of the simulation process and reached physically acceptable values. The errors of individual parameters are also very low (Table 2).

The overall agreement between the experimental and calculated energy levels is good since the rms value for the final fit was $17 \mathrm{~cm}^{-1}$ (Table 2). As for individual c.f. splittings, only for a few levels, there are large discrepancies between the calculated and experimental energies. There was no way to avoid these discrepancies since no other level assignment could be done. No systematic discrepancies could be detected which indicates that, at least, the free ion effects are well reproduced. The low rms deviation of $17 \mathrm{~cm}^{-1}$ achieved with the simulation with $C_{2 \mathrm{v}}$ point symmetry instead of the real $C_{\mathrm{s}}$ one, is rather surprising and indicates, in contrast to the structural data, a higher pseudosymmetry than the actual $C_{\mathrm{s}}$ symmetry. The low $B_{2}^{2}$ value would suggest even higher symmetry but this is con-

Table 2

Free ion and crystal field parameters for $\operatorname{Pr}^{3+}$ in $\mathrm{K}_{2}(\mathrm{La}, \mathrm{Pr}) \mathrm{Cl}_{5}$ and $\mathrm{K}_{2} \mathrm{YF}_{5}$

\begin{tabular}{lcc}
\hline Parameter & $\mathrm{K}_{2} \mathrm{PrCl}_{5}{ }^{\mathrm{a}}\left(\mathrm{cm}^{-1}\right)$ & $\mathrm{K}_{2} \mathrm{YF}_{5}[15]^{\mathrm{b}}\left(\mathrm{cm}^{-1}\right)$ \\
\hline$F^{0}$ & $9557(1)^{\mathrm{c}}$ & \\
$F^{2}$ & $68,299(10)$ & 68,116 \\
$F^{4}$ & $50,328(28)$ & 49,925 \\
$F^{6}$ & $33,156(20)$ & 32,031 \\
$\alpha$ & $20.33(5)$ & 18.37 \\
$\beta$ & $-649(5)$ & -751.18 \\
$\gamma$ & $1297(6)$ & {$[1470]^{\mathrm{d}}$} \\
$\zeta_{4 \mathrm{f}}$ & $741.3(7)$ & 746.2 \\
$B_{0}^{2}$ & $515(7)$ & 651 \\
$B_{2}^{2}$ & $159(7)$ & -122 \\
$B_{0}^{4}$ & $-899(19)$ & 1129 \\
$B_{2}^{4}$ & $-590(14)$ & 1213 \\
$B_{4}^{4}$ & $515(15)$ & -1046 \\
$B_{0}^{6}$ & $404(27)$ & -237 \\
$B_{2}^{6}$ & $-33(19)$ & 343 \\
$B_{4}^{6}$ & $326(23)$ & -283 \\
$B_{6}^{6}$ & $119(24)$ & 99 \\
$N_{V}$ & 1730 & 2592 \\
rms deviation $\sigma$ & 17 & 21 \\
Levels & $86 / 91$ & $40 / 91$ \\
\hline
\end{tabular}

${ }^{\text {a }}$ Present work.

b The Slater integrals $F^{2}, F^{4}$, and $F^{6}$ were transformed from the Racah parameters $E^{1}, E^{2}$, and $E^{3}$ with the aid of the following equations: $F^{2}=(225 / 42)\left(7 E^{1}+143 E^{2}+11 E^{3}\right) ; \quad F^{4}=(1089 / 77)\left(E^{1}-130 E^{2}+4 E^{3}\right) ;$ $F^{6}=(7361.64 / 462)\left(E^{1}+35 E^{2}-7 E^{3}\right)$.

${ }^{c}$ The values in brackets are the estimated standard deviations of the parameters.

${ }^{\mathrm{d}}$ The parameter values in square brackets were not varied in the simulations. tradicted by the rather important values of the other $\left(B_{2}^{4}\right.$, $B_{2}^{6}$, and $B_{6}^{6}$ ) parameter values which describe a similar symmetry decrease (Table 2). Of course, the monocapped trigonal prismatic coordination around the $\mathrm{Pr}^{3+}$ ion prevents any pseudosymmetry higher than $C_{2 \mathrm{v}}$. As for the use of the real $C_{\mathrm{s}}$ symmetry in the simulation, the good results obtained with the use of the higher $C_{2 \mathrm{v}}$ point symmetry gives as such no justification to this decrease in symmetry since the simulation of the c.f. effect on the $4 \mathrm{f}^{2}$ energy level scheme of the $\mathrm{Pr}^{3+}$ ion in $\mathrm{K}_{2}(\mathrm{La}, \mathrm{Pr}) \mathrm{Cl}_{5}$ has clearly achieved its practical objective. On the other hand, there is no reliable manner to predict which kind of scheme to follow in the decrease in symmetry since the arbitrary inclusion of the six additional c.f. parameters required by the $C_{\mathrm{s}}$ symmetry-in comparison with $C_{2 v}$ - seems unjustified and may well result in a physically meaningless parametrization. It may be evident, however, that the fit between the experimental and calculated energy level schemes would be better as far as the rms deviation is concerned. The calculations of the c.f. parameters were also done for $C_{\mathrm{s}}$ symmetry including Marvin integrals [26] and $P^{k}$ parameters. The final results of these calculations show somewhat lower standard deviations. However, when $M^{0}$ and $P^{2}$ parameters were varied freely $\left(M^{2} / M^{0}=0.56\right.$ and $M^{4} /$ $\left.M^{0}=0.38\right)$ in the fitting procedure, the calculations lead to the parameter values which were devoid of physical meaning [26].

\subsection{Crystal field strength in $\mathrm{K}_{2}(\mathrm{La}, \mathrm{Pr}) \mathrm{Cl}_{5}$ and $\mathrm{K}_{2}(\mathrm{Y}, \mathrm{Pr}) \mathrm{F}_{5}$}

The low value $\left(1730 \mathrm{~cm}^{-1}\right)$ of the c.f. strength parameter, $N_{V}$, needs some explanation. The main reason to this low values is, of course, the fact that all the individual c.f. parameters assumed low values, usually less than $600 \mathrm{~cm}^{-1}$. This is rather unusual though the c.f. effect on the $4 \mathrm{f}$ electrons is inherently weak due to the well shielded position of the $4 \mathrm{f}$ orbitals [31]. On the other hand, the low coordination number 7 seems to favor a strong c.f. effect [44] whereas the contribution of the soft chloride ligand to the weak c.f. effect should not be forgotten, either. For instance, for the rare earth oxychloride $(\mathrm{ROCl})$ series, the electrostatic point charge calculations have shown that the contribution of the five chloride ligands on the c.f. effect on the $\mathrm{R}^{3+}$ ion is much less than that of the four oxides [53].

The low c.f. strength parameter value for the $\mathrm{K}_{2}(\mathrm{La}, \mathrm{Pr}) \mathrm{Cl}_{5}$ series is in good agreement with that obtained for the corresponding fluoride system, $\mathrm{Pr}^{3+}$ doped $\mathrm{K}_{2} \mathrm{YF}_{5}$ [15]. In $\mathrm{K}_{2} \mathrm{YF}_{5}$, the $\mathrm{Pr}^{3+}$ ion is imposed to a strong c.f. effect because the $\operatorname{Pr}^{3+}$ ion is replacing a much smaller $\mathrm{Y}^{3+}$ host cation $[43,44]$ as shown by the ionic radii 1.126 and $0.96 \AA$, respectively, for the coordination number eight (there is no data available for $\mathrm{CN}=7$ ) [54]. The $\mathrm{Pr}-\mathrm{F}$ distances are considerably shorter than the $\mathrm{Pr}-\mathrm{Cl}$ ones which structural effect leads to a stronger c.f. effect, too. A closer comparison between the individual c.f. field parameters reveals that the parameter sets for these two halide hosts 
are very much different, even the signs of the parameters are usually different with the exception of the $B_{0}^{2}$ (and $B_{6}^{6}$ ) parameters (Table 2). It may be argued, that the data on the $\mathrm{Pr}^{3+}$ doped $\mathrm{K}_{2} \mathrm{YF}_{5}$ system is far from complete, only 40 levels out of 91 , and this may significantly contribute to the differences in the parametrization schemes. However, the comparison of the energy level schemes of the $\mathrm{Pr}^{3+}$ ion in these two hosts shows that these are not at all similar. In addition to the inherent greater overall splitting of the ${ }^{2 S+1} \mathrm{~L}_{J}$ levels in $\mathrm{K}_{2} \mathrm{YF}_{5}$ because of the stronger c.f. effect also the individual c.f. splittings within the ${ }^{2 S+1} \mathrm{~L}_{J}$ levels are different even if downscaled to the same overall splitting. As a conclusion, the c.f. effect on the $\mathrm{Pr}^{3+}$ ion in these two halide host is very different despite the apparent isotypic crystal structures.

As for the free ion interactions, the differences in the Coulombic repulsion terms (the Slater integrals) between the chloride and fluoride hosts are small but systematic. The $F^{k}$ values are smaller for the fluoride host and this can be seen in the barycenter energy level scheme of the
$\mathrm{Pr}^{3+}$ ion as lower energies. This evolution resembles to the nephelauxetic ("cloud expansion") effect which states that along with the increasing delocalization (covalence) of the valence electrons even the $4 \mathrm{f}$ orbitals - and thus the $4 f^{2}$ electron configuration, too-could expand. However, the present observation is in contrast to the conventional wisdom according to which the covalent effects should be more pronounced in the chloride host than in the fluoride one [55]. The comparison between the chloride and fluoride hosts is made difficult, however, because of the fact that the two host cations, lanthanum and yttrium, respectively, may have some effect.

\subsection{Simulation of the paramagnetic susceptibility}

The inverse of magnetic susceptibility data, $1 / \chi_{\text {obs }}$, measured for the $\mathrm{K}_{2} \mathrm{PrCl}_{5}$ single crystal as a function of temperature, is shown in Fig. 8. Also depicted are the magnetic susceptibility data, $\chi_{\mathrm{obs}}=f(T)$, and, in the inset, the low temperature part of the $1 / \chi=f(T)$ curve. Accord-
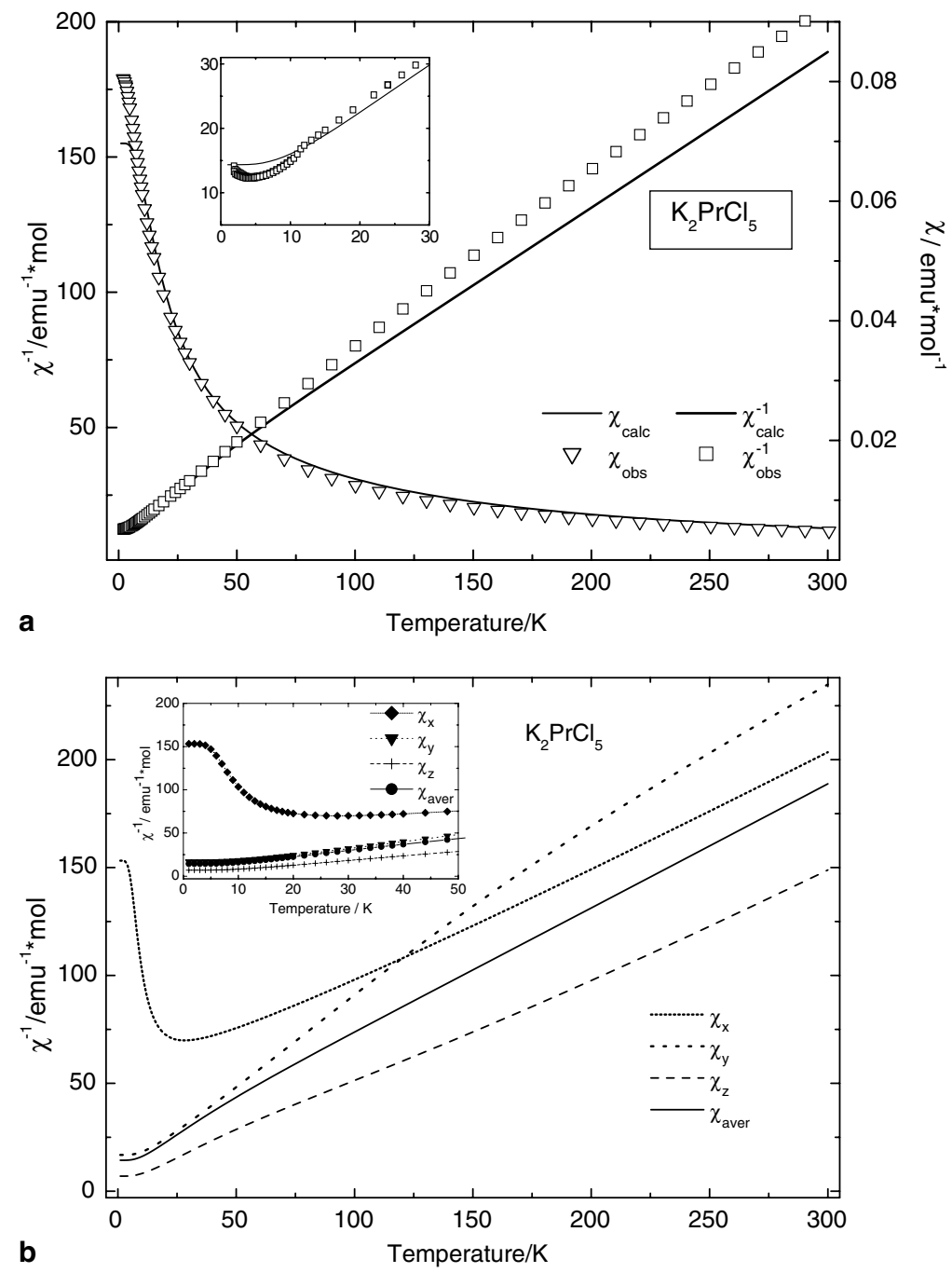

Fig. 8. The temperature evolution of the experimental paramagnetic susceptibility $(\chi)$ as well as the experimental (a) and calculated inverse paramagnetic susceptibilities $\left(\chi^{-1}\right)$ of $\mathrm{K}_{2} \mathrm{PrCl}_{5}$ (b). The inset presents the low temperature behavior of $\chi^{-1}$. 
ing to the magnetic susceptibility data available, no crystallographic phase transitions seem to be present in $\mathrm{K}_{2} \mathrm{PrCl}_{5}$ since the smooth evolution of the magnetic susceptibility as a function of temperature showed no peculiarities usually accompanying such transitions. No magnetic, e.g. antiferromagnetic, ordering or other magnetic phase transitions were observed between 4 and $298 \mathrm{~K}$ in the susceptibility-temperature $\left(\chi_{\mathrm{obs}}-T\right)$ curve, either.

At the temperature range from 1.9 to $5.5 \mathrm{~K}$ a maximum can be detected in magnetic susceptibility data (from 0.0778 at $1.9 \mathrm{~K}$ to $0.08872 \mathrm{emumol}^{-1}$ at $3.1 \mathrm{~K}$ and to 0.08843 at $5.5 \mathrm{~K}$ ). This can suggest weak antiferromagnetic ordering as it was proposed earlier [26]. In fact, the magnetic and EPR studies of different polynuclear and heteronuclear systems have shown weak $\mathrm{Ln}-\mathrm{Cu}$ interactions whereas Ln-Ln interactions were significantly weaker and determined exchange integrals were very small [56-59].

The inverse susceptibility data were fitted to the CurieWeiss law $(\chi=C /(T-\theta))$ and the resulting linear plot was superimposed with the experimental data. The poor fit at low temperatures suggests that the Curie-Weiss law cannot account for the susceptibility observed in the entire temperature range. Accordingly, the fitting was carried out only for the linear part of the $1 / \chi-T$ curves at the high temperature range. The Curie constant $(C)$ and the Weiss constant ( $\theta$ ) equal to $1.74 \mathrm{emuKmol}^{-1}$ and $-28 \mathrm{~K}$, respectively, were obtained for $\mathrm{K}_{2} \mathrm{PrCl}_{5}$. The negative Weiss constant $\theta$ value suggests antiferromagnetic ordering at lower temperatures [60]. The room temperature effective magnetic moment $\mu_{\text {eff }}$ values observed experimentally (3.45 BM), calculated without (3.64 BM) and with the c.f. contribution (3.57 BM) agree rather well with the theoretical ground level free ion value $\left(\mu_{\mathrm{eff}}=g_{J}(J(J+1))^{1 / 2}=3.58 \mathrm{BM}[61]\right)$. The results of the magnetic susceptibility $\left(\chi_{\mathrm{M}}\right)$ of $\mathrm{K}_{2} \mathrm{PrCl}_{5}$ changes somewhat from that reported in [26] after an increase of the sample mass used in the measurements and a correction for the quartz tube.

The magnetic coupling between $\mathrm{R}^{3+}$ ions is usually weak resulting in a Curie-Weiss type paramagnetic behavior down to low temperatures. However, at temperatures lower than $20 \mathrm{~K}$, significant deviation from the linear Curie-Weiss behavior was observed in the $1 / \chi_{\text {obs }}$ curve for $\mathrm{K}_{2} \mathrm{PrCl}_{5}$. This difference may be attributed to the c.f. effect on the $4 f^{2}$ energy level scheme since very weak if any exchange interactions in the $\mathrm{Pr}^{3+}$ sublattice seem to be present $[56,57,62]$. The c.f. effect rises from the fact that the c.f. components of the ${ }^{2 S+1} \mathrm{~L}_{J}$ levels of the $\mathrm{Pr}^{3+}$ ions are unequally occupied at low temperatures. The experimental behavior of the inverse susceptibility at low temperature was in fact very well reproduced by using the van Vleck formalism (Eq. (3)) and the wave functions and level energies obtained from the c.f. simulation of the spectral data (Section 3.4). This indicates the correctness and high quality of the c.f. simulation of the $4 \mathrm{f}^{2}$ energy level scheme in $\mathrm{K}_{2} \mathrm{PrCl}_{5}$. If the experimental and calculated $\chi_{\mathrm{M}}$ versus $T$ curves are compared, excellent agreement is observed. However, replacing this relationship by $\chi^{-1}$ versus $T$ shows a discrepancy between the calculated and experimental data at higher temperatures.

The strong anisotropy of the inverse magnetic susceptibility at low temperatures shown by the calculations (Fig. 8b) supports the ion-pair interaction in the polymeric of the crystal structure. According to the structural data, the $\mathrm{PrCl}_{7}$ units are interconnected to infinite chains along the crystallographic $b$-axis. The structural results show the different $\mathrm{Pr}^{3+}-\mathrm{Pr}^{3+}$ distances: the intrachain $\mathrm{Pr}^{3+}$ $\mathrm{Pr}^{3+}$ distance is rather short $(4.550 \AA)$ whereas the next $\mathrm{Pr}^{3+}-\operatorname{Pr}^{3+}$ distances are much longer, $6.891 \AA$. Thus the strong anisotropy of the inverse magnetic susceptibility at low temperatures is caused by the wave functions and eigenvalues of the two to three lowest lying crystal field levels of $\mathrm{Pr}^{3+}$ in chain.

\section{Conclusions}

The absorption and excitation spectra of the potassium lanthanum praseodymium ternary chlorides, $\mathrm{K}_{2}(\mathrm{La}, \mathrm{Pr}) \mathrm{Cl}_{5}$, single crystals is dominated in the UV region by bands $(175,190,220,245,263$ and $323 \mathrm{~nm})$ due to the parity allowed interconfigurational $4 \mathrm{f}^{2} \rightarrow 4 \mathrm{f}^{1} 5 \mathrm{~d}^{1}$ transitions. Since five components are expected for the $C_{\mathrm{s}}$ point symmetry of the $\mathrm{Pr}^{3+}$ site more work should be devoted to this aspect. The ${ }^{1} \mathrm{~S}_{0}$ level could be detected in the UV-VUV excitation spectra which is not usual.

The absorption spectra of $\mathrm{K}_{2}(\mathrm{La}, \mathrm{Pr}) \mathrm{Cl}_{5}$ in the visible and IR regions comprise the parity forbidden $4 \mathrm{f} \rightarrow 4 \mathrm{f}$ transitions from the ground ${ }^{3} \mathrm{H}_{4}$ level to the excited ${ }^{3} \mathrm{H}_{6},{ }^{3} \mathrm{~F}_{2-4}$, ${ }^{1} \mathrm{G}_{4},{ }^{1} \mathrm{D}_{2},{ }^{3} \mathrm{P}_{0-2}$, and ${ }^{1} \mathrm{I}_{6}$ levels. The $J$ degeneracy was lifted completely in accordance with the $C_{\mathrm{s}}$ point symmetry appropriate to the $\operatorname{Pr}^{3+}$ site. Practically all Stark components were found for these ${ }^{2 S+1} \mathrm{~L}_{J}$ levels.

The luminescence spectrum of $\mathrm{Pr}^{3+}$ in $\mathrm{K}_{2} \mathrm{LaCl}_{5}$ between 435 and $850 \mathrm{~nm}$ originates mainly from transitions from the ${ }^{3} \mathrm{P}_{0}$ level to the ${ }^{3} \mathrm{H}_{4-6}$ and ${ }^{3} \mathrm{~F}_{2-4}$ levels but the ${ }^{3} \mathrm{P}_{0} \rightarrow{ }^{3} \mathrm{H}_{4}$ and ${ }^{3} \mathrm{P}_{0} \rightarrow{ }^{3} \mathrm{~F}_{2}$ transitions dominate. Very weak emission from the ${ }^{1} \mathrm{D}_{2}$ level was observed, too. In the range of $900-1500 \mathrm{~nm}$ the ${ }^{1} \mathrm{I}_{6} \rightarrow{ }^{1} \mathrm{G}_{4},{ }^{1} \mathrm{G}_{4} \rightarrow{ }^{3} \mathrm{H}_{5},{ }^{3} \mathrm{P}_{0} \rightarrow{ }^{1} \mathrm{G}_{4}$ emission was recorded as well as ${ }^{1} D_{2} \rightarrow{ }^{1} G_{4}$ what is not very common. The analysis of the luminescence spectra of $\mathrm{K}_{2} \mathrm{LaCl}_{5}: \mathrm{Pr}^{3+}$ yielded all the Stark levels for the ${ }^{3} \mathrm{H}_{4,5,6}$ and ${ }^{3} \mathrm{~F}_{2,3,4}$ levels, in total 54 c.f. levels.

The set of 86 c.f. energy levels out of the 91 c.f. levels was used in the calculation of the crystal field effect accounting simultaneously both the free ion and the c.f. contributions. The entire $4 \mathrm{f}^{2}$ basis set of the 91 c.f. levels was used in the simulation, too. The calculations yielded a low rms value of $17 \mathrm{~cm}^{-1}$ and a set of parameters of high quality and reliability as reflected by the low esd's of all the parameters. The results obtained for the $C_{2 \mathrm{v}}$ point symmetry give no practical or scientific justification to a decrease in symmetry to the actual $C_{\mathrm{s}}$ symmetry since no new information about the crystal field effect will be achieved. Although the low coordination number 7 seems to favor a strong c.f. effect, the low value of the c.f. strength param- 
eter $\left(N_{V}=1730 \mathrm{~cm}^{-1}\right)$ may be explained by the low contribution of the chloride ligands.

The significant deviation from the linear Curie-Weiss behavior in the inverse paramagnetic susceptibility $\left(1 / \chi_{\text {obs }}\right)$ for $\mathrm{K}_{2} \mathrm{PrCl}_{5}$ was very well reproduced by using the van Vleck formalism and the wave functions and level energies obtained from the c.f. simulation of the spectral data. This indicates the correctness and high quality of the c.f. simulation of the $4 \mathrm{f}^{2}$ energy level scheme in $\mathrm{K}_{2}(\mathrm{La}, \mathrm{Pr}) \mathrm{Cl}_{5}$. The strong anisotropy of the inverse magnetic susceptibility at low temperatures shown by the calculations probably results from strong interactions between the intrachain $\operatorname{Pr}^{3+}-\operatorname{Pr}^{3+}$ ions when compared to the interchain interactions.

\section{Acknowledgements}

Financial support from the Academy of Finland, European Union (J.H., J.L., J.C.) and KBN grant no. 3 T09A 02426 (J.L., J.C.) is gratefully acknowledged. The authors thank Piotr Solorz (DESY synchrotron, Hamburg Synchrotron Radiation Laboratory HASYLAB, Germany) for the help in measuring the synchrotron spectra. For the use of the $\mathrm{XeCl}$ excimer laser, the authors are indebted to Prof. W. Stręk (Institute of Low Temperatures and Structure Research, Polish Academy of Sciences, Wrocław). Two of us (J.L., J.C.) are grateful to Dr. M. Karbowiak for helpful discussions.

\section{References}

[1] T. Jüstel, J.-C. Krupa, D. Wiechert, J. Lumin. 93 (2001) 173.

[2] G. Blasse, B.C. Grabmaier, Luminescent Materials, Springer, Berlin, 1994.

[3] M.F. Reid, L. van Pieterson, R.T. Wegh, A. Meijerink, Phys. Rev. B $62(2000) 14744$.

[4] L. Zhang, C. Pedrini, C. Madej, C. Dujardin, J.C. Gacon, B. Moine, I. Kamenskikh, A. Belsky, D.A. Shaw, M.A. MacDonald, P. Mesnard, C. Fouassier, J.C. van't Spijker, C.W.E. van Eijk, Radiat. Eff. Defects Solids 150 (1999) 47.

[5] W.W. Piper, J.A. de Luca, F.S. Ham, J. Lumin. 8 (1974) 344.

[6] E. Bayer, J. Leppert, B.C. Grabmaier, G. Blasse, Appl. Phys. A 61 (1995) 177.

[7] J.C. van't Spijker, P. Dorenbos, J.T.M. de Haas, C.W.E. van Eijk, H.U. Güdel, K. Krämer, Radiat. Meas. 24 (1995) 379.

[8] J.C. van’t Spijker, P. Dorenbos, C.W.E. van Eijk, H.U. Güdel, K. Krämer, J. Lumin. 85 (1999) 1.

[9] P. Dorenbos, Phys. Rev. B 62 (2000) 15650.

[10] M. Karbowiak, N. Edelstein, Z. Gajek, J. Drozdzynski, Spectrochim. Acta A 54 (1998) 2025.

[11] H.P. Andres, K. Krämer, H.U. Güdel, Phys. Rev. B 54 (1996) 3830.

[12] K. Krämer, H.U. Güdel, J. Alloys Comp. 207/208 (1994) 128.

[13] K. Krämer, L. Keller, P. Fischer, B. Jung, N.M. Edelstein, H.U. Güdel, G. Meyer, J. Solid State Chem. 103 (1993) 152.

[14] H.G. Brittain, G. Meyer, J. Solid State Chem. 54 (1984) 156.

[15] M. Yin, J.-C. Krupa, E. Antic-Fidancev, V.N. Makhov, N.M. Khaidukov, J. Lumin. 101 (2003) 79.

[16] N. Martin, R. Mahiou, P. Boutinaud, J.C. Cousseins, J. Alloys Comp. 323-324 (2001) 303.

[17] G. Meyer, E. Hüttl, Z. Anorg. Allg. Chem. 497 (1983) 191.

[18] G. Meyer, J. Soose, A. Montz, V. Vitt, Th. Holjes, Z. Anorg. Allg. Chem. 521 (1985) 161;
J. Legendziewicz, G. Meyer, N. Gerlitzki, J. Cybińska, unpublished results.

[19] G. Meyer, M.S. Wickleder, Simple and Complex Halides, in: K.A. Gschneidner Jr., L. Eyring (Eds.), Handbook on Physics and Chemistry of Rare Earths, vol. 28, Elsevier, Amsterdam, 2000, p. 53.

[20] K. Güde, C. Hebecker, Z. Naturforsch. B 40 (1985) 864.

[21] B.G. Wybourne, Spectroscopic Properties of Rare Earths, Interscience, New York, 1965.

[22] W.T. Carnall, H. Crosswhite, H.M. Crosswhite, J.P. Hessler, N.M Edelstein, J.G. Conway, G.V. Shalimoff, R. Sarup, J. Chem. Phys. 72 (1980) 5089.

[23] C. Görller-Walrand, K. Binnemans, Rationalization of Crystal-Field Parametrization, in: K.A. Gschneidner Jr., L. Eyring (Eds.), Handbook on Physics and Chemistry of Rare Earths, vol. 23, Elsevier, Amsterdam, 1996, Chapter 155.

[24] C.A. Morrison, R.P. Leavitt, Spectroscopic Properties of Triply Ionized Lanthanides in Transparent Host Crystals, in: K.A. Gschneidner Jr., L. Eyring (Eds.), Handbook on Physics and Chemistry of Rare Earths, vol. 5, North-Holland, Amsterdam, 1982, Chapter 46.

[25] J.L. PratherMonograph, 19, US National Bureau of Standards, Washington, 1961.

[26] J. Cybińska, J. Sokolnicki, J. Legendziewicz, G. Meyer, J. Alloys Comp. 341 (2002) 115;

J. Legendziewicz, J. Cybińska, G. Meyer, Opt. Mater. 24 (2003) 197; J. Legendziewicz, M. Karbowiak, J. Cybińska, unpublished results.

[27] P. Porcher, Computer Program REEL for the Simulation of $d^{N}$ and $f^{N}$ Configurations Involving the Real and Complex Crystal Field Parameters, C.N.R.S., Meudon, France, 1989, unpublished.

[28] J.C. Bernier, P. Poix, L'Act. Chim. 2 (1978) 7.

[29] J.H. van Vleck, The Theory of Electric and Magnetic Susceptibilities, Oxford University Press, London, 1965.

[30] J. van Vleck, J. Appl. Phys. 39 (1968) 365.

[31] S. Hüfner, Optical Spectra of Transparent Rare Earth Compounds, Academic Press, London UK, 1978.

[32] D. Garcia, M. Faucher, Crystal Field in Non-Metallic (Rare-Earth) Compounds, in: K.A. Gschneidner Jr., L. Eyring (Eds.), Handbook on Physics and Chemistry of Rare Earths, vol. 21, Elsevier, Amsterdam, 1996, Chapter 144.

[33] R.P. Leavitt, C.A. Morrison, D.E. Wortman, Report TR-1673, Harry Diamond Laboratories, Adelphi, MD, 1975.

[34] O.L. Malta, Chem. Phys. Lett. 87 (1982) 27.

[35] O.L. Malta, Chem. Phys. Lett. 88 (1982) 353.

[36] A.J. Freeman, J.P. Desclaux, J. Magn. Magn. Mater. 12 (1979) 11.

[37] F. Jollet, C. Noguera, N. Thormat, M. Gautier, P. Duraud, Phys. Rev. B 42 (1990) 7587.

[38] A.A. Kaminskii, Crystalline Lasers: Physical Processes and Operating Schemes, CRC Press, Boca Raton, FL, 1996.

[39] P. Porcher, Program SOMAILLE for Point Charge Lattice Sum Calculations, C.N.R.S., Meudon, France, 1987.

[40] F. Auzel, O.L. Malta, J. Phys. (Fr.) 44 (1983) 201.

[41] N.C. Chang, J.B. Gruber, R.P. Leavitt, C.A. Morrison, J. Chem. Phys. 76 (1982) 3877.

[42] S. Sato, J. Phys. Soc. Jpn. 41 (1976) 913.

[43] E. Antic-Fidancev, J. Hölsä, M. Lastusaari, A. Lupei, Phys. Rev. B 64 (2001) 195108

[44] E. Antic-Fidancev, J. Hölsä, M. Lastusaari, A. Lupei, J. Solid State Chem. 171 (2003) 282.

[45] E. Antic-Fidancev, M. Lemaitre-Blaise, P. Porcher, J. Hölsä, J. Chem. Soc.: Faraday Trans. 87 (1991) 3625.

[46] G. Oczko, J. Legendziewicz, J. Hanuza, J. Gliński, L. Macalik, Acta Phys. Pol. A 90 (1996) 431.

[47] J. Legendziewicz, Z. Ciunik, P. Gawryszewska, J. Sokolnicki, J. Alloys Comp. 225 (1995) 372.

[48] J. Legendziewicz, J. Alloys Comp. 300-301 (2000) 71.

[49] M.P. Hehlen, H. Reisen, H.U. Güdel, Inorg. Chem. 30 (1991) 2273.

[50] M. Wenzel, M. Altwein, R. Demirbilek, B. Len, J. Heber, J. Kübler, B. Bleeker, A. Meijerink, J. Alloys Comp. 300-301 (2000) 479-482.

[51] E. Antic-Fidancev, J. Alloys Comp. 300-301 (2000) 2. 
[52] E. Antic-Fidancev, J. Hölsä, M. Lastusaari, J. Phys. Condens. Matter 15 (2003) 863.

[53] J. Hölsä, M. Lastusaari, unpublished data.

[54] R.D. Shannon, Acta Crystallogr. A 32 (1976) 751.

[55] E. Antic-Fidancev, M. Lemaitre-Blaise, P. Caro, New J. Chem. 11 (1987) 467.

[56] G. Oczko, J. Legendziewicz, J. Mrozinski, G. Meyer, J. Alloys Comp. 275-277 (1998) 219.

[57] J. Legendziewicz, B. Keller, I. Turowska-Tyrk, W. Wojciechowski, New J. Chem. 23 (1999) 1097.
[58] Yu.V. Yablokov, V.K. Voronkova, J. Legendziewicz, M. Borzechowska, Solid State Phys. 41 (1999) 2154.

[59] K.M. Salikhov, R.T. Galeer, V.K. Voronkova, Yu.V. Yablokov, J. Legendziewicz, Appl. Magn. Reson. 14 (1998) 457.

[60] C. Leycuras, H. Le Gall, M. Guillot, A. Marchand, J. Appl. Phys. 55 (1984) 2161.

[61] J. Hölsä, M. Lastusaari, J. Niittykoski, R. Sáez Puche, Phys. Chem. Chem. Phys. 4 (2002) 3091.

[62] F. Wiss, N.P. Raju, A.S. Wills, J.E. Greedan, Int. J. Inorg. Mater. 2 (2000) 53. 